\title{
Loving the mess: navigating diversity and conflict in social values for sustainability
}

\author{
Jasper O. Kenter ${ }^{1}$ (D) . Christopher M. Raymond ${ }^{2,3,4}$. Carena J. van Riper ${ }^{5}$ Elaine Azzopardi ${ }^{1}$ Michelle R. Brear ${ }^{6,7}$. \\ Fulvia Calcagni $^{8} \cdot \operatorname{lan}$ Christie $^{9} \cdot$ Michael Christie $^{10} \cdot$ Anne Fordham $^{11} \cdot$ Rachelle K. Gould $^{12}$. Christopher D. Ives ${ }^{13}$. \\ Adam P. Hejnowicz ${ }^{14}$. Richard Gunton ${ }^{15}$. Andra-loana Horcea-Milcu ${ }^{16}$. Dave Kendal ${ }^{17}$. Jakub Kronenberg ${ }^{18}$. \\ Julian R. Massenberg ${ }^{19} \cdot$ Seb O'Connor ${ }^{20} \cdot$ Neil Ravenscroft $^{21}$ • Andrea Rawluk ${ }^{22} \cdot$ Ivan J. Raymond ${ }^{23}$. \\ Jorge Rodríguez-Morales ${ }^{24}$. Samarthia Thankappan ${ }^{1}$
}

Received: 17 May 2019 / Accepted: 9 August 2019 / Published online: 24 August 2019

(c) The Author(s) 2019

\begin{abstract}
This paper concludes a special feature of Sustainability Science that explores a broad range of social value theoretical traditions, such as religious studies, social psychology, indigenous knowledge, economics, sociology, and philosophy. We introduce a novel transdisciplinary conceptual framework that revolves around concepts of 'lenses' and 'tensions' to help navigate value diversity. First, we consider the notion of lenses: perspectives on value and valuation along diverse dimensions that describe what values focus on, how their sociality is envisioned, and what epistemic and procedural assumptions are made. We characterise fourteen of such dimensions. This provides a foundation for exploration of seven areas of tension, between: (1) the values of individuals vs collectives; (2) values as discrete and held vs embedded and constructed; (3) value as static or changeable; (4) valuation as descriptive vs normative and transformative; (5) social vs relational values; (6) different rationalities and their relation to value integration; (7) degrees of acknowledgment of the role of power in navigating value conflicts. In doing so, we embrace the 'mess' of diversity, yet also provide a framework to organise this mess and support and encourage active transdisciplinary collaboration. We identify key research areas where such collaborations can be harnessed for sustainability transformation. Here it is crucial to understand how certain social value lenses are privileged over others and build capacity in decision-making for understanding and drawing on multiple value, epistemic and procedural lenses.
\end{abstract}

Keywords Shared values $\cdot$ Relational values $\cdot$ Environmental values $\cdot$ Knowledge brokering $\cdot$ Epistemology . Interdisciplinarity $\cdot$ Ecosystem services $\cdot$ Nature's contributions to people

\section{Introduction}

Social values inquiry draws upon a rich range and depth of theoretical traditions, each with its own assumptions related to how values are conceptualised, elicited and related to other constructs. This paper concludes a Special Feature

Handled by Osamu Saito, United Nations University Institute for the Advanced Study of Sustainability, Japan.

Jasper O. Kenter

jasper.kenter@york.ac.uk

$\triangle$ Christopher M. Raymond christopher.raymond@helsinki.fi

Extended author information available on the last page of the article of Sustainability Science that has brought together a broad range of these traditions. We seek to build bridges across these traditions, considering their diverse social value lenses and areas of tension between them. We embrace the 'mess' of diversity, yet also bring an innovative framing to this mess to support and encourage active transdisciplinary collaboration for social values as a key concern of the environmental social sciences (Chan et al. 2018, Ives and Kendal 2014; Kenter et al. 2014a, 2015, 2016a; Kronenberg 2014; Pascual et al. 2017; Parks and Gowdy, 2013; Rawluk et al. 2017; Raymond et al. 2014, 2019; Scholte et al. 2015; van Riper et al. 2017).

Researchers and practitioners conceptualise social values in ways that connect to particular understandings of the world based on history, culture, geography, experience, 


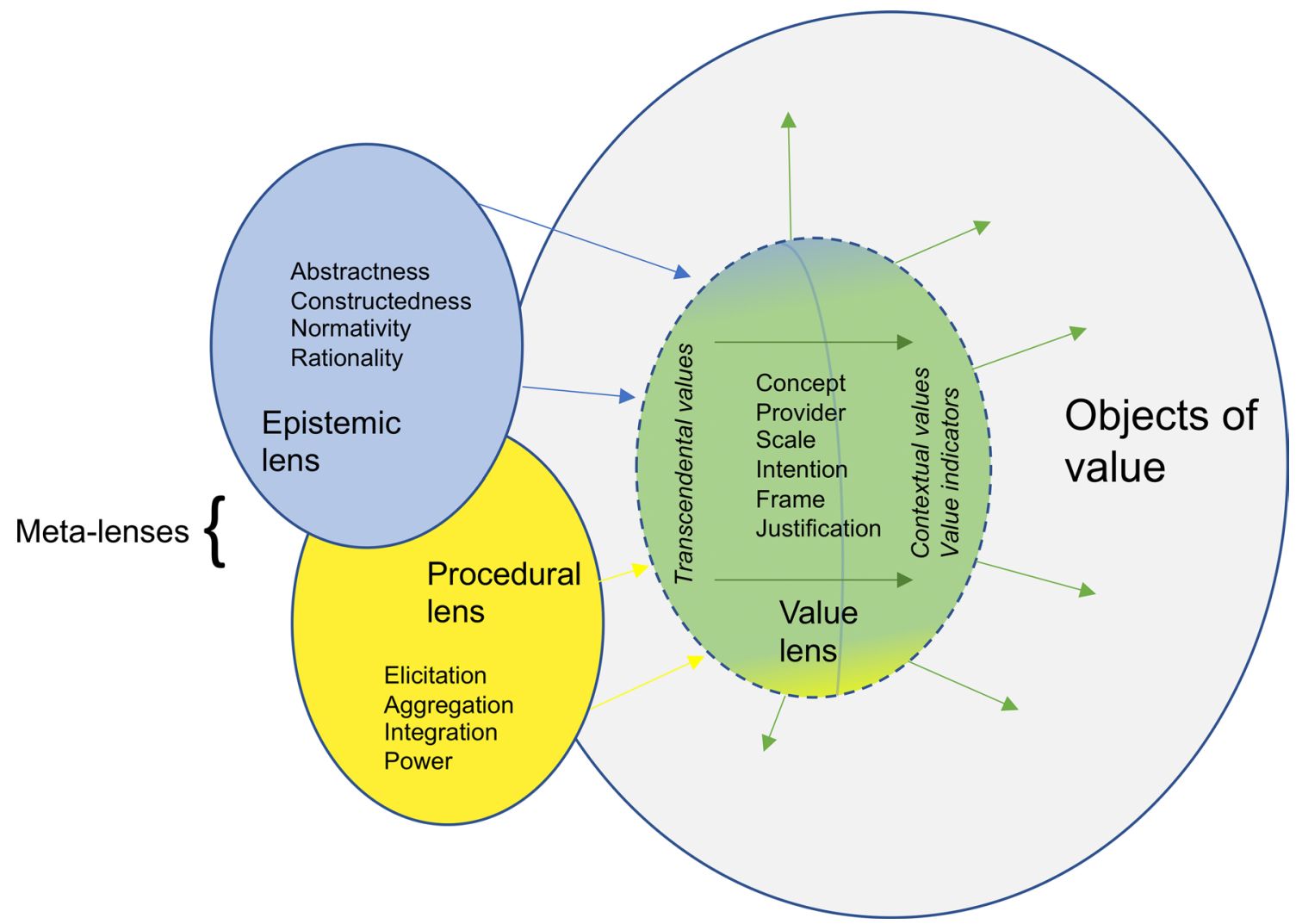

Fig. 1 Social values as lenses on what matters: what is or should be important to us, about, in and as the world, with two types of metalenses: the epistemic lens and procedural lens, and the dimensions (Table 1) of value associated with the three types of lenses. The value lens is depicted in two parts, with broad, transcendental val-

and embodiment (Williams 2014). This means that no single disciplinary framework can fully integrate the many understandings of social values. We adopt a post-normal view grounded in epistemic pluralism that suggests there is no 'one correct way' of conceptualising social values; each provides a limited perspective to be scrutinised in democratic debate and decision-making (Funtowicz and Ravetz 1993; Ainscough et al. 2018). Post-normal science addresses complex, wicked problems, where facts are uncertain, stakes are high, and decisions are urgent. Today's deeply challenging environmental sustainability issues provide a prime example. Here, the choices about what and how we research are inherently normative, because all problem descriptions partially result from the value lenses through which issues are viewed. Different lenses give rise to competing knowledge claims, which can be addressed through deliberative processes of knowledge co-production that extend peer review from expert-only to a transdisciplinary community also involving practitioners, policy makers and citizens (Funtowicz and Ravetz 1993; Strand 2017).

In this paper, we develop a novel transdisciplinary conceptual framework to help navigate the messy reality of ues guiding specific, contextual values and their indicators. While value lenses and objects of worthiness are depicted as separate entities, whether they are assumed separable will differ per epistemic lens (hence porous boundary of value lens)

social values research and practice. Central to this framework is a consideration of social values as lenses of worthiness: lenses of what is considered to matter. Underpinning these lenses sit diverse meta-lenses, which explain how values are conceived and assessed. We highlight two key types of meta-lens; the epistemic lens and the procedural lens (Fig. 1). We identify fourteen dimensions along which the different social value lenses and meta-lenses of diverse theoretical traditions can be discriminated (Table 1). Armed with this framework, we then investigate central areas of tension between different social value theoretical traditions, identifying key avenues for future research. These tensions emerged from a deliberative global expert workshop in York, UK, in June 2018 (Box 1; also see Eriksson et al. 2019), to which authors representing each of the papers within this Feature were invited. The papers were submitted in response to an open call for contributions (Raymond et al. 2018). They draw on a wide variety of theoretical bases, highlighting the importance of social values as a boundary concept (Kenter 2016a; Steger et al. 2018).

This is the first paper to present a comprehensive framework for drawing together knowledge across the wide 


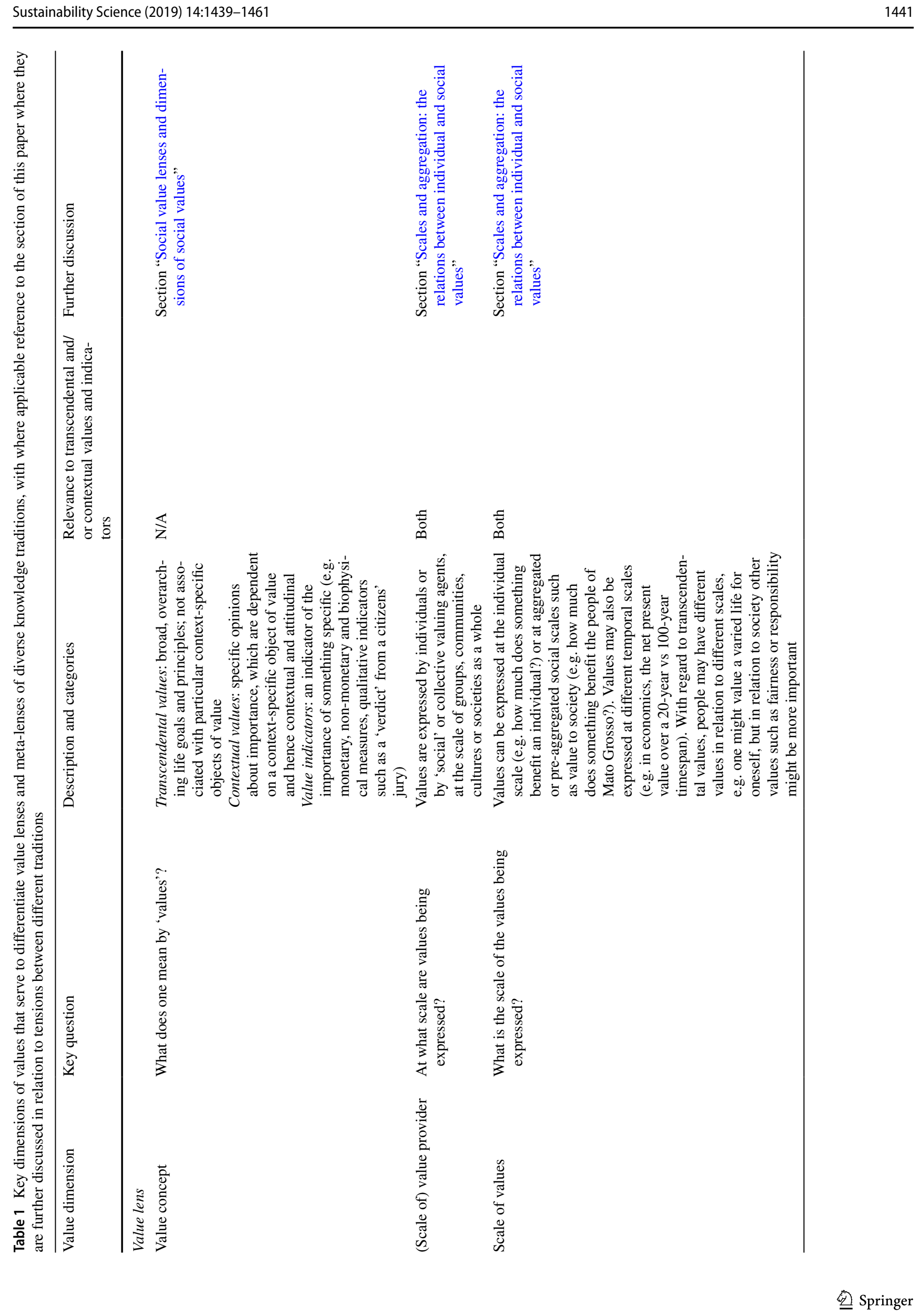




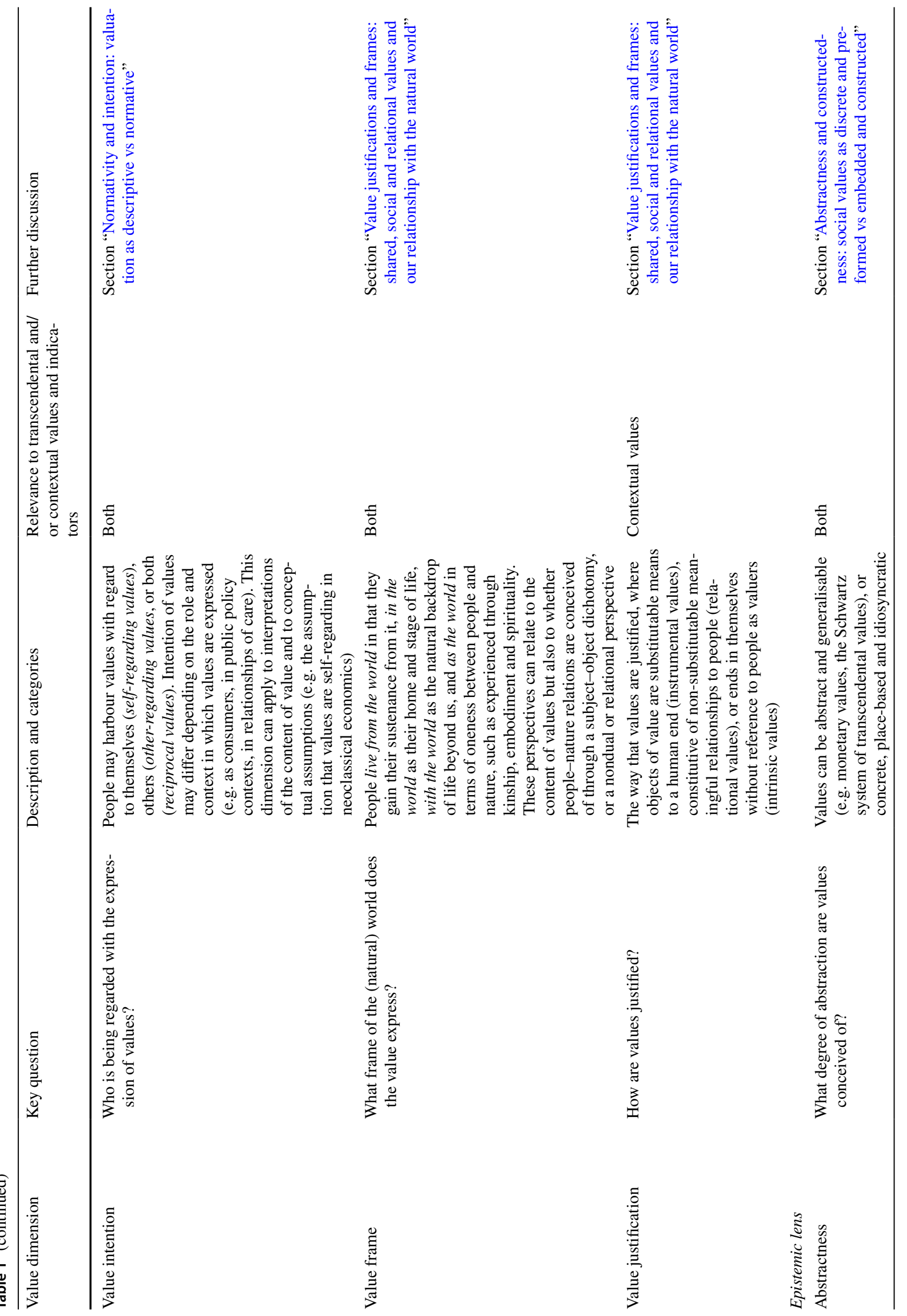




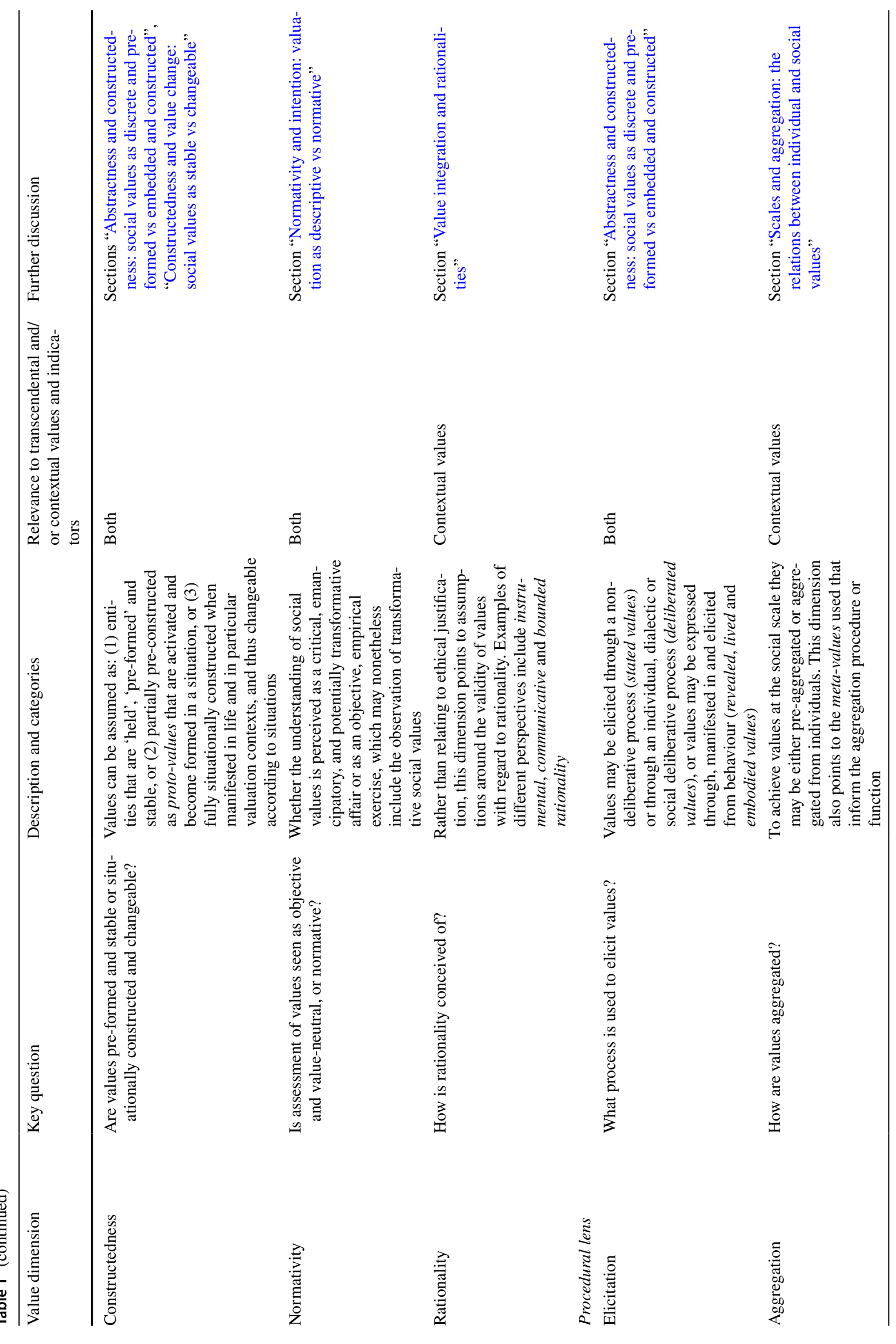




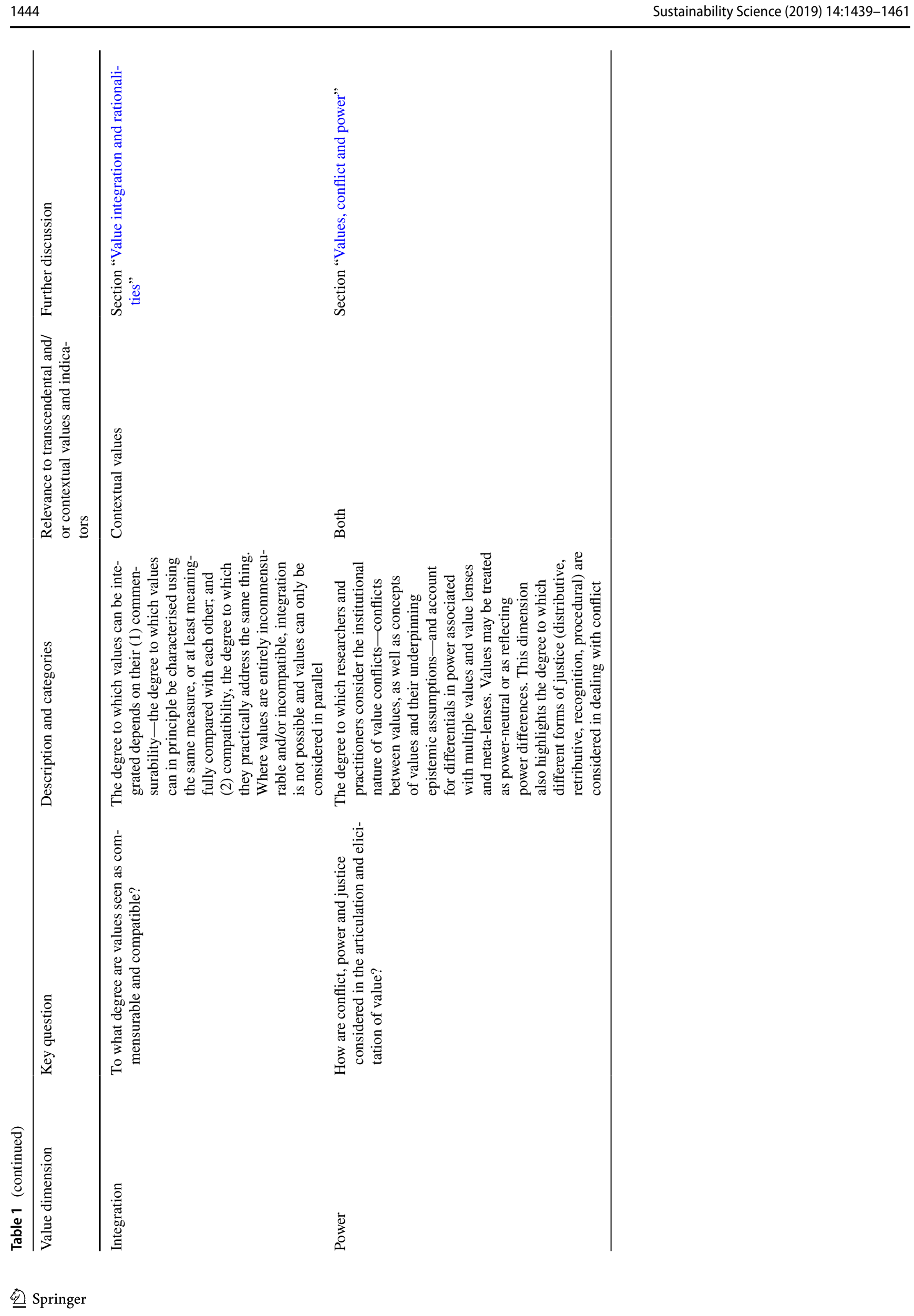


range of traditions that consider social values of sustainability, from more realist to more relativist, from positivist to diverse interpretivist and critical approaches. However, rather than rehash well-known spectra of ontology and epistemology, we identify specific tensions to more precisely investigate key pinch points in relation to social values and valuation. While we focus on environmental sustainability, our contribution may also benefit other fields where social values are a key concern, such as energy and health.

The exploration of tensions between theoretical traditions is an opportunity for personal and collective growth and a means for advancing scholarship, not least because it highlights different understandings of and approaches to social values that may not be self-evident when those from different backgrounds collaborate. Tensions and lenses need to be explicitly and rigorously considered if the goal is to incorporate a diversity of worldviews into environmental decision-making, as proposed by, for example, the Intergovernmental Science-Policy Platform on Biodiversity and Ecosystem Services (IPBES) (Pascual et al. 2017; Díaz et al. 2018; Christie et al. 2019b). The Intergovernmental Panel on Climate Change has long been heavily dominated by natural science worldviews, but also here there are demands for a more diverse knowledge base and challenging implicit social value lenses (Hulme 2011; Ford et al. 2016). Through a mutual recognition of differences, viewing sustainability issues through different lenses of social values provides a richer and more comprehensive picture and can offer a more inclusive and more relevant value-evidence basis for sustainability transformation. Thus, we clarify issues at the frontier of social values for sustainability in the light of these tensions, providing a forward-looking and constructive agenda for transdisciplinary engagement with sustainability science.

\section{Box 1: Deliberation process within the author team}

An open call for Special Feature abstracts was publicised in February 2018 in Sustainability Science (Raymond et al. 2018). Forty-seven submissions were received, of which 18 were selected by the co-editors (CR, AR, CvR, DK, JK) based on criteria including academic quality from peer review of abstracts, disciplinary and geographic diversity, and gender balance. An author from each paper was invited to attend a workshop at the University of York, UK, funded by the Valuing Nature Programme. The goals of the workshop were to identify linkages across papers, facilitate deliberation on broader social values knowledge across diverse disciplines, and synthesise this new knowledge in a collective article. A diversity of perspectives were represented, including environmental science and ecology, human geography, sociology, psychology, ecological and mainstream economics, anthropology, philosophy, and business and religious studies.
The first day of the workshop involved five sessions, each containing three paper presentations and 45 min discussion. At the conclusion of each session, workshop participants added their individual reflections to an online interface. The co-editors distilled these insights into five sets of topics: (1) value scales and hierarchies; (2) integration, plurality and conflict; (3) values and value-activation; (4) power and value change; and (5) overall conceptualisation of social values. The following day, participants deliberated on these topic sets in small subgroups over the course of two discussion sessions facilitated by the co-editors, allowing each participant to engage with two sets in detail and learn from the group's insights. Each subgroup focused on identifying areas of tension between different knowledge traditions and their lenses, and future directions for research. A final plenary session further refined tensions, and identified key conclusions and cross-linkages. Following the workshop, reports from each subgroup were prepared, which were further elaborated into mini-articles by subgroups of the authors through collaboration and discussion via email and videoconference. The lead author (JK) and co-editors then iteratively reorganised the partially overlapping content of these outputs into the structure of lenses, dimensions and tensions as presented here.

\section{Social value lenses and dimensions of social values}

There are many understandings of social values. Central understandings include values as overarching principles, values pertaining to a common good or society as a whole, and values that become shared through processes of socialisation, including deliberation and internalisation (Kenter et al. 2015; van Riper et al. 2018; Ishihara 2018). Diverse knowledge and appraisal traditions each harbour one or more social value lenses. These lenses articulate both what values are focused upon and how their sociality is envisioned. The lenses of diverse traditions can be characterised and differentiated along multiple dimensions of social values, such as the scale of values or the process by which they are elicited (Table 1). For example, a research tradition may focus on values at the societal scale, expressed by a social unit larger than an individual (e.g. a local community) and/or through a social process (e.g. a group workshop). In addition, different traditions harbour meta-lenses (Fig. 1), comprising specific theories and bodies of scientific or local and indigenous knowledge that articulate different perspectives on social valuation, with their own epistemologies and explicit or implicit meta-values: values about values, for example, about how values should be aggregated (Kenter et al. 2016a). Meta-lenses thus frame the social perspective and position of the viewer with respect to how social values and their 
dynamics are perceived and expressed. We consider social value lenses and meta-lenses to be a dynamic medium of perception, articulation and understanding through which the world is interpreted and evaluated: they are therefore open, reflexive and responsive, and not fixed, unidirectional or unchanging.

Meta-lenses also help us understand how social value lenses are associated with and applied to different purposes, exemplified by the diverse papers in this Special Feature. Some meta-lenses focus on understanding relations between values and behaviour (van Riper et al. 2019), others are geared towards value formation and co-construction (Kenter et al. 2016c; Calcagni et al. 2019); lived values (Brear and Mbonane 2019); values embedded in cultural institutions (Gould et al. 2019; Ives and Kidwell 2019; Christie et al. $2019 b$ ); or value-awareness and activation in relation to wellbeing and sustainability (Raymond and Raymond 2019). Other meta-lenses are critical and emancipatory (O'Connor and Kenter 2019; Ravenscroft 2019). Finally, some are themselves associated with studying how meta-lenses are adopted in valuation institutions (Rawluk et al. 2019; Horcea-Milcu et al. 2019; Massenberg 2019).

While a complete discussion of the knowledge paradigms embedded within differing meta-lenses of diverse traditions is beyond the scope of this paper, the teleological or purposeful nature of social value lenses can be explained by two key types of meta-lens: the epistemic and procedural meta-lens (Fig. 1), or, for brevity, simply epistemic lens and procedural lens. The epistemic lens considers how we harbour, create and know 'value', as well as the philosophical orientation of knowledge traditions that guides researchers' social value lenses. The procedural lens describes the types of processes used to attain and explain social values.

To help understand similarities and tensions between different social value traditions, we consider a range of dimensions of their value, epistemic and procedural lenses (Table 1). Here we build on foundational work by Kenter et al. (2014a, 2015), who developed a framework for differentiating between types of social values according to how they have been conceived in different traditions. At the basis of this lies differentiation between broad, transcendental and specific, contextual values and their indicators. Transcendental values are broad notions of what is important in life; they are not attached to a context-specific object of value and serve to guide specific, contextual values. For example, a broad desire for harmony with nature might lead us to express context-specific opinions of value around conserving a particular habitat, which may be assessed in terms of quantitative or qualitative indicators through some form of valuation. It is important to note that transcendental values, while they transcend the specific contexts where we ascribe importance to particular things, are by definition generalisable or divorced from cultural contexts more broadly. For example, what constitutes harmony, nature, and harmony with nature might be conceived of quite differently between different cultures. In practice, transcendental and contextual values can be closely entwined, particularly where transcendental values are strongly embedded in particular relationships (including with non-humans) and not meaningfully separable from the importance ascribed to those relationships (Gould et al. 2019).

This nomenclature extended research by Rokeach (1973) that differentiated 'held' values (i.e. guiding principles and life goals) and 'assigned' values (i.e. opinions on the values of particulars), where the first were thought to predict the latter, both through the process of deduction and a relational realm of felt experiences (Schroeder 2013). However, Kenter et al. (2015) noted that opinions on the values of particulars could semantically be both held and assigned, and that values might thirdly refer to measures and other indicators. Further, the terms held and assigned have come to be associated with a particular knowledge tradition, which makes implicit epistemic assumptions that values are pre-formed, discretely observable mental entities. These assumptions are shared by some but contested by other traditions (we will discuss this further in the next section). Thus, transcendental and contextual should not just be seen as new terms for Rokeach's old concepts, but along with indicators as a way to distinguish between the three main meanings of the word value that does not seek to prejudice towards the implicit epistemic assumptions associated with the idea that values can be held or assigned.

Kenter et al. (2015) also discriminated between different types of shared and social values along dimensions of value provider, scale, intention, and elicitation process. To provide for a framework that can tackle knowledge of a broader multidisciplinary nature, such as reflected in this feature and other important recent knowledge developments in the field (e.g. a special issue of Current Opinion on Environmental Sustainability on relational values; Chan et al. 2018), we add further dimensions and organise them in relation to the value, epistemic and procedural lenses (Fig. 1; Table 1). We add two dimensions associated with the value lens: value frame and value justification. These dimensions categorise values in relation to framings of how the world matters to people and differentiate between intrinsic, relational and instrumental values. Within the epistemic lens, abstractness, constructedness, normativity and rationality denote whether values are considered abstract or place-based, pre-formed or constructed, descriptive or normative, and which conception of rationality justifies them. Associated with the procedural lens, the closely related dimensions of aggregation, integration and power denote differences in the way that value plurality and conflict are perceived and managed.

As an example of the relations among value, epistemic and procedural lenses, and some of their associated 
dimensions, in this feature O'Connor and Kenter (2019) investigated a particular type of social values, 'articulated intrinsic values', focusing on marine ecosystems employing ethnographic stakeholder interviews. The social value lens was the worthiness of the 'more-than-human' world, reflecting other-regarding values on the dimension of intention, individual and communal values in terms of scale, and intrinsic values in relation to justification (Table 1). The underpinning epistemic lens in this research was interpretivist and perspectivist. This lens characterised values as place-based and situationally constructed on the dimensions of abstractness and constructedness, and the dimension of normativity highlights an epistemic lens that seeks to emancipate the more-than-human world. The authors deployed a procedural lens along the dimensions of elicitation and aggregation that highlighted the purpose of the exercise as feeding into a deliberative democratic process that should be used to weigh and aggregate the different values expressed. The procedural lens thus emphasised meta-values of participation, deliberation and, in relation to the power dimension, fairness in terms of procedural and recognition justice, through which the social value lens of articulated intrinsic values was considered.

We do not claim this new set of dimensions fully and finally articulates all possible lenses and meta-lenses across the vast diversity of social values literature. However, it reflects a substantial extension and evolution of understanding from Kenter et al. (2015), which was largely grounded in ecological economics, to a much more comprehensive interdisciplinary underpinning.

Combining and comparing social values across theoretical traditions can lead to tensions, because these traditions utilise different social value lenses and meta-lenses reflecting differences in the way values are conceived, elicited and applied. Following Goldstein (2015), a commitment to conceptual and theoretical openness in interdisciplinary teams generates conceptual tension at various levels, to diverse degrees, and to variable effects. In turn, tension and conflict open up established theories and concepts for dialogue and revision. Lenses and tensions are closely related, because lenses can be seen as a key source of tension, or conversely, are themselves characterised by one's position in areas of tension. Thus, the notion of lenses and tensions across different dimensions provide a useful means of scaffolding to 'frame the mess' of diversity in the broad field of social values.

Tensions can arise at the level of the content of values, value lenses, and meta-lenses. For example, a typical conflict between pro-development and pro-conservation values is not just a matter of valuing different things, as what values are included will be different depending on the dimensions of the value lens used, such as its scale (e.g. individual, communal, societal), and on the epistemic and procedural meta-lens underpinning it, such as in terms of what value justifications are considered and how questions of value aggregation and power are addressed.

We discuss seven key areas of tension. We focus on the following, gradually shifting emphasis from ontology of social values to their application: (1) social values as aggregated from the individual scale vs being pre-aggregated at a social scale (related to the value provider, scale of values, and aggregation dimensions); (2) social values as discrete, pre-formed and held vs being embedded, implicit, and constructed through their manifestation in deliberation and action; and (3) values as static or changeable (both related to the constructedness dimension); (4) social values through a descriptive vs normative lens (intention and normativity); (5) the relations between social, shared, relational, intrinsic and instrumental values (frame and justification dimensions); (6) tensions relating to value integration; and (7) tensions in the degree to which power is acknowledged in navigating value conflict (power dimension).

\section{Tensions in the theory and practice of social values}

\section{Scales and aggregation: the relations between individual and social values}

The first area of tension arises from a basic question: what makes social values social? Although interpreted differently, essentially the idea of values being social relates to society. This raises the question of how society and its values are represented, particularly whether societal values are considered an independent construct or an aggregation of individual values. Thus far, most lenses have either focused on individualistic or collective indicators, and there is only limited understanding of the relations between them (Kenter et al. 2014a).

Some social values cannot be reduced to the individual scale of expression. As an example, take the UK Marine Policy Statement, which formalises a "shared vision" of "clean, healthy, safe, productive and biologically diverse oceans and seas". ${ }^{1}$ This signifies shared social values across value lens dimensions: the statement was made by governments to represent society as a whole and express transcendental values at the social scale, established through a social process. Individuals are socialised: therefore all individual values reflect social values to a certain degree (Kenter et al. 2015). Individuals may also experience, represent and enact shared values such as expressed by the policy statement

\footnotetext{
$\overline{1}$ https://www.gov.uk/government/publications/uk-marine-polic y-statement.
} 

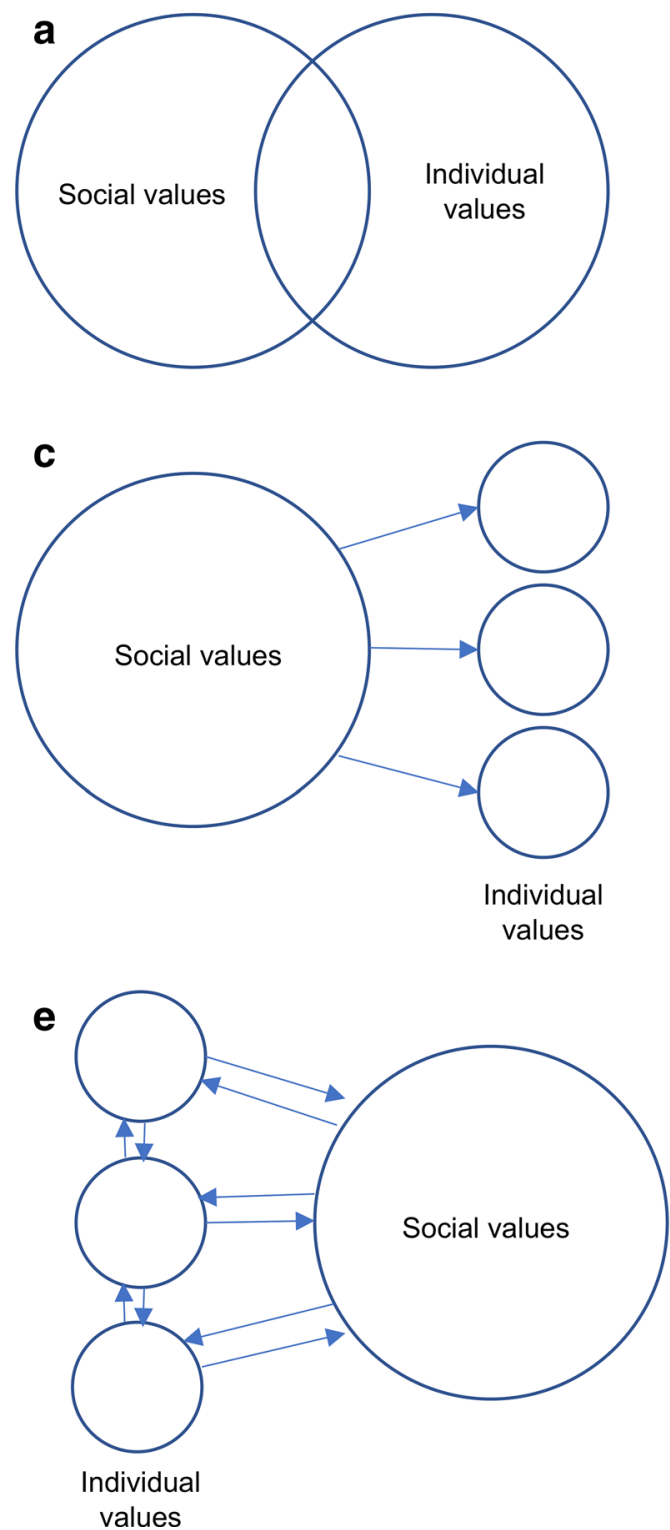

Fig. 2 Different ways of conceiving the relation between social values (as value to society in terms of contextual values, and as values in relation to society in terms of transcendental values) and individual values: as a distinct but overlapping sets of values; b social values as

above. However, how can individual values be aggregated to form social values?

The relationship between individual values and social values at a societal scale (i.e. as value to society in terms of contextual values, and as values in relation to society in terms of transcendental values), can be thought of in at least five ways, which inform different social value lenses (Fig. 2). In Fig. 2a, at the contextual value level, the aggregate of individual and social values are different but may overlap, while at the transcendental level people may express multiple sets of potentially overlapping and clashing values (e.g. consumer values vs citizen values; Kenyon et al. b

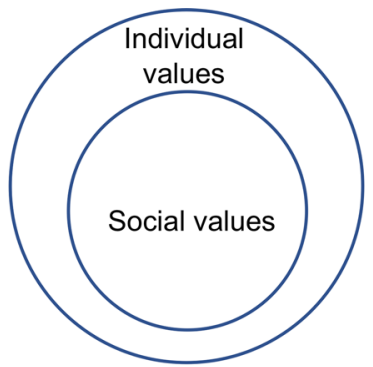

\section{d}

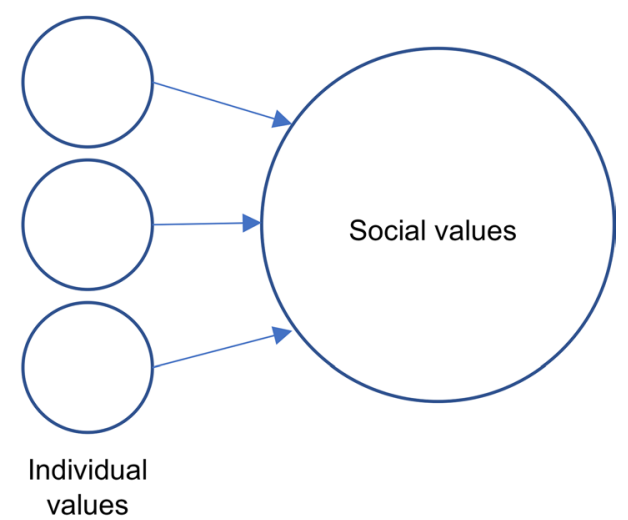

a subset of the aggregate of individual values; $\mathbf{c}$ social values as (partially) predicting individual values; $\mathbf{d}$ social values as (partially) predicted by individual values; and e social values in dynamic interplay with individual values

2001). The second perspective is that of a nested diagram (Fig. 2b), which indicates that any method of aggregating values, whether through analytical approaches or deliberative processes, is bound to exclude some, typically because of power relations (Ernstson 2013; Hockley 2014; OrchardWebb et al. 2016). Under this model, social values are always a subset of the pool of individual values and rarely approximate the totality of pooled values. The third and fourth figures (Fig. 2c, d) depict a causal relationship, where either social values predict individual ones or vice versa (e.g. van Riper et al. 2019). This reflects the view that individuals represent their society, but consider it through their 


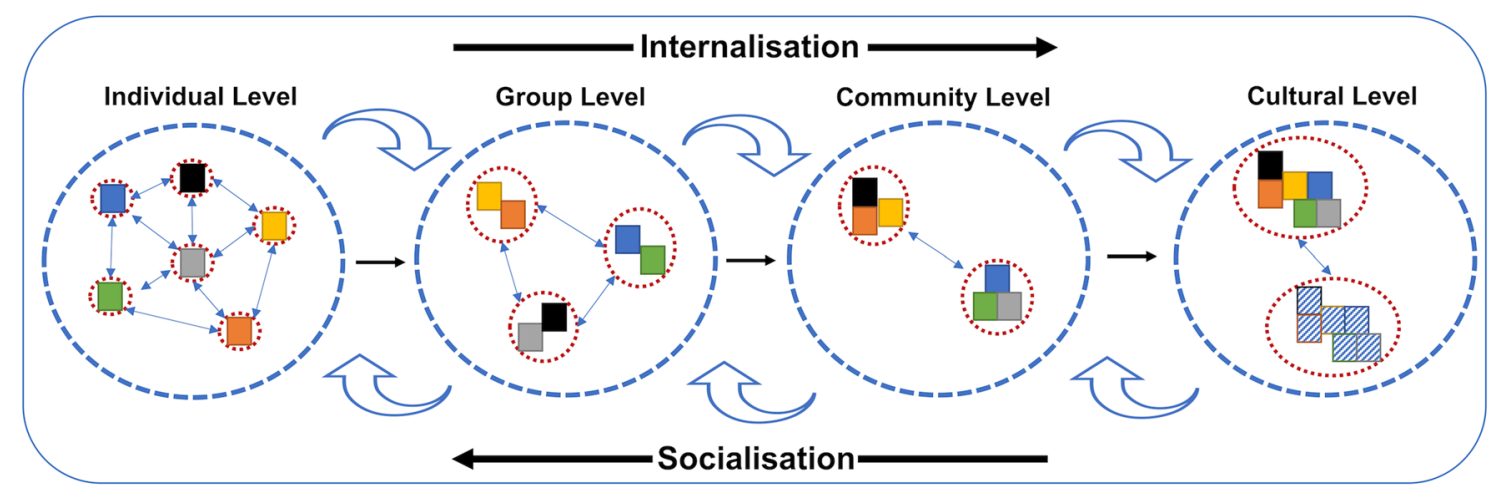

Fig. 3 Conceptual model showing there are multiple levels of value providers-including individual, group, community, and cultural-that have different configurations of individual and aggregated values as reflected by the multi-coloured units within each sphere. The different levels interact through feedbacks that amplify

individual perceptions and experiences. The fifth (Fig. 2e) is a dynamic view of causal relationships, whereby individual values and shared social values can be seen as situated within a dynamic interplay where values 'transfer' from various social to individual provider levels and vice versa (e.g. Fordham and Robinson 2019).

Further research on the interrelations between individual and social values is needed within and across each of the five models in Fig. 2. Also, comparative research between the overlapping, nested, causal, and dynamic perspectives will be of particular value in considering what factors influence the difference between (aggregate) individual and (preaggregated) social values, and how values transfer between these levels. Moreover, the use of more than one model will likely provide added insight into complex and contested issues, as investigation of shared values is particularly salient in situations of social conflict and disagreement among interest groups (Kenter et al. 2014b). All of these models are sensitive to the differences between aggregate individual and social values, and as such, it is important for policy and practice to recognise what might influence degrees of difference, and how these differences relate with associated lenses used to assess values. Greater understanding of the differences between aggregated individual values and social values will also enable researchers to identify appropriate methods for establishing a more comprehensive perspective.

Extending the ontological tension between (aggregated) individual and social values, we further complicate this relationship and distinguish social values across multiple levels of value providers. Relationships between individual and social values function within complex systems can be organised hierarchically (van Riper et al. 2018). Previous research has identified and grouped values provided at the individual, group (extended) community, and whole culture and society levels (Manfredo et al. 2014; Kenter et al. 2015) or dampen the relationships of values and the boundaries between them, which are permeable. Internalisation and socialisation are the key processes that facilitate the scaling up and down of values within hierarchies of value providers

that accommodate interactions within these hierarchies. In line with arguments that values 'scale up' to higher levels (Kendal and Raymond, 2019), the values expressed by groups are in part an aggregate of individuals' values but may also be entirely new 'emergent' phenomena (Fig. 3). In addition to this ontological tension between individual values and values of larger social units, there are practical tensions between values that exist at different provider levels. This tension is generated by value hierarchies in finding sustainability solutions, as well as processes for aligning values across multiple scales such as the need for decision-making processes to prioritise between the values of smaller versus larger collectives. This is further complicated by different procedural lenses on the commensurability and compatibility of values and lenses (see section "Constructedness and value change: social values as stable vs changeable"), and on how to navigate conflict and address power issues (see section "Value integration and rationalities").

We distinguish two mechanisms by which values are transferred between levels. The first is socialisation, and it occurs over extended periods of time (Ishihara 2018) as well as when values are formed in shorter-term social processes, such as group deliberation (Kenter et al. 2016c; Kendal and Raymond 2019). The values that emerge from socialisation can be solidified through social learning and social norms that regulate practices within a collective (Irvine et al. 2016). The second is internalisation. Over time, individuals observe interpersonal dynamics and adjust their orientations to align with a group (Calcagni et al. 2019, van Riper et al. 2018). This is grounded in personal reflections and intraindividual deliberation. Together, these mechanisms can yield changes in systemic understanding of others' values, improved capacity for individuals to recognise their own orientations, and knowledge of why changes in values occur at different levels of social organisation (Kenter et al. 2016c). 
Future research should explore how values are shifted when moving across different hierarchical levels. This is particularly relevant in light of sustainability transitions because the scaling up and down of values reflects the continuously changing conditions in society and offers an opportunity to ensure the incorporation of multiple values into decisionmaking (also see Fordham and Robinson 2019).

\section{Abstractness and constructedness: social values as discrete and pre-formed vs embedded and constructed}

An in important tension between different epistemic lenses revolves around whether values are believed to exist as discrete entities, pre-formed and held by people, or as only coming into existence when manifested, including in deliberation (Ravenscroft 2019) and as 'lived values' in individual and collective behaviour (Brear and Mbonane 2019, Gould et al. 2019). In terms of contextual values, valuation researchers have pointed out these are frequently poorly formed in unfamiliar environmental contexts (Jobstvogt et al. 2014a, b; Urama and Hodge 2006). However, there is also a tension in the conception of transcendental values as: (1) held as, (a) relatively singular and stable across a human lifespan, or (b) multiple sets of contextually activated values; or (2) not held but constructed and manifested in response to individual, group and social-ecological context. This tension also relates to the dimension of abstractness associated with epistemic lenses and discussed in more detail by Rawluk et al. (2019). This dimension clarifies whether values are seen to be: (1) distinctly isolated as an abstract, discrete entity (e.g. in this feature van Riper et al. 2019; Christie et al. 2019a); or (2) not abstractable from broader cultural constructs such as worldviews, cosmologies or narratives, and, in relation to specific values, places, without losing meaning (e.g. in this feature Gould et al. 2019; O'Connor and Kenter 2019; Ives and Kidwell 2019).

The tension between epistemic lenses that see social values as abstract, discrete and held vs embedded, situationally constructed and manifested has important implications for social valuation: from the first perspective, associated with for example social psychology, conventional economics and public participation GIS, values are considered as self-existing mental entities that can be isolated and interrogated. In other perspectives, associated with humanities and deliberative ecological economics, values are understood as embedded in cultural and institutional contexts. Here the language of value 'capture' becomes inappropriate (Ravenscroft 2019). These latter perspectives are also less likely to see values within a power vacuum, rather considering them as part of an institutional setup shaped by discursive structures of power and knowledge-we will return to questions of power in "Value integration and rationalities".
Some synthesis between the two positions is possible through the concept of proto-values (Kenter et al. 2016a), where people neither hold fully formed values nor are they an evaluative tabula rasa. Proto-values mediate between the transcendental (broad) and contextual (specific) concepts of values, and between the abstract and pre-formed and constructed and situated. They are not fully formed values but exist as a broad value-inclination or attitude that becomes more moulded by and embedded within context through a key set of institutional and contextual process factors, which can include the lens and meta-lenses of the particular social values tradition. Proto-values provide an avenue for allowing some generalisation, whilst acknowledging valuation as a process of value formation that is highly context-dependent. However, the concept is in need of further development and empirical exploration.

Constructedness and embeddedness also raise questions about the social and spatiotemporal scales within which this embedding is situated. Scales influence how research is conducted and looking through differing spatiotemporal value lenses can yield conflicting perspectives on sustainability solutions (Gunton et al. 2014). Future research should be sensitive to the effects of spatial and temporal variation in values and focus on mechanisms that can bridge multiple spatiotemporal lenses. Deliberative and interpretive participatory mapping exercises could consider how spatially explicit social values are culturally and institutionally embedded. This approach could also provide insight on how values map onto the geographies of relevant environmental conditions, evaluate how group deliberation can synthesise values across a range of spatiotemporal scales, and reconcile mismatches between scales of people's values and ecosystem processes. Furthermore, the degree to which values are seen as isolatable from the contexts of place, time and culture will influence the types of interventions that are considered: whether it makes sense to develop generalised interventions focused specifically on encouraging pro-environmental values, or whether they should be highly situated and placebased, or focus on a value formation process that is geared towards activation and translation of proto-values to particular contexts.

\section{Constructedness and value change: social values as stable vs changeable}

A further tension related to the epistemic dimension of constructedness is whether values are perceived as stable or changeable. This is of particular importance and increasing debate within the sustainability field, because the degree to which values are pre-formed and stable will more generally determine the usefulness of interventions targeting values (e.g. mindfulness or targeted deliberations) as a strategy for sustainability transformation. This debate within the 
context of pro-environmental value and behaviour change is most relevant to consideration of transcendental values. These are generally seen as more stable than contextual values (Schwartz et al. 2012), yet they are expressed to different degrees depending on the salience of issues (Trope and Liberman 2010) and centrality to the evaluator's identity (Stets and Burke 2000). Both across and within traditions such as social psychology, deliberative ecological economics and sociology, different procedural and epistemic lenses conflict in terms of their perceptions on how easily transcendental values can be changed (e.g. Manfredo et al. 2017; Raymond and Kenter 2016; Everard et al. 2016; Ives and Fischer 2017). Others argue that a notable gap between transcendental values and actions (Kollmuss and Agyeman 2002) makes this mission irrelevant. That is, while values may activate certain behavioural intentions, constraints posed by people's environments limit their expression. In contrast, the positive psychology literature (Raymond and Raymond 2019) does not focus on value change but instead on individuals acting congruently with their values, with congruence associated with higher wellbeing and psychological health. This literature brings a strong focus to how values are operationalised and behaviourally manifested in different contexts and to awareness raising processes to deliberate on and express values within context, including specific decision-making processes. Drawing on Bardi and Goodwin (2011), awareness raising represents a 'priming' process for value change and/or expression. Awareness raising processes can be considered across two pathways: a healthy values pathway whereby certain value types are associated with healthy outcomes for the individual, and a value activation pathway which considers whether selfidentified values are congruently expressed (Raymond and Raymond 2019). Mindfulness, operationalised as (1) awareness ('what is mindfulness'), (2) skill (mindful awareness of values in decision-making) and (3) mindset (mindful orientation), is a way to promote wellbeing and sustainable behaviour through the pathway of value activation. Mindfulness has thus emerged as an important process variable to understand the elicitation and expression of values (Wamsler et al. 2018) with clear relevance for sustainability science. However, thus far the value lens of positive psychology has almost solely focused on internalisation with individuals. To act as mediator for value change at the communal, cultural and societal level, mindfulness also needs to be linked to socialisation processes.

Sustainability science is increasingly focused on the causes and effects of change, and values can be conceived of as both a driver and an outcome of that change. Societal values form the foundation of institutional rules and knowledge systems that are part of managing and governing natural resources (Gavin et al. 2018). At the same time, complex environmental change such as climate change can become a catalyst for changes in values (O'Brien and Wolf 2010). Crisis triggered by natural hazards shortens even more the feedbacks between values as drivers and outcomes. As such, the opportunity space for responses to risks is delineated and shaped by deliberated, reconciled societal, communal and group values, but at the same time, crisis may be the most rapid trigger for radical changes in our principles and life goals, and this in turn is likely to affect contextual values. When the consequences of environmental changes become evident for people, they may become more aware of the diverse values of nature, compared to 'normal' times. Crises of natural resources or climate change thus can become opportunities to form and (re-)connect to shared values of nature if the focus is on how to think and act together towards these values.

Further research is needed that considers to what degree and how rapidly transcendental values can change, why a focus on contextual factors and values may not be sufficient (IPBES 2019), how does value change 'ripple out' (Everard et al. 2016) to the societal and cultural level, what interventions are most effective at achieving such change, and to what degree value change acts as a precursor to or an effect of changing behaviour. There is also a need for interdisciplinary scholars to reconcile the approaches of value change and value congruence, notably if wellbeing as a construct is considered as much a process as an outcome, and to relate individualistic processes such as mindfulness more strongly to social values, socialisation processes and social outcomes.

\section{Normativity and intention: valuation as descriptive vs normative}

The next tension relates to whether the formation and understanding of social values is perceived as teleologically normative: a critical, emancipatory, and potentially transformative affair (e.g. in this feature O'Connor and Kenter 2019; Brear and Mbonane 2019; Horcea-Milcu et al. 2019; Ravenscroft 2019), or as descriptive: an objective, empirical exercise (e.g. Christie et al. 2019b; Raymond and Raymond 2019), which nonetheless may include the observation of transformative social values (e.g. Fordham and Robinson 2019). Through a critical meta-lens, (shared) social values can be seen as a (shared) understanding of the common good. The ethical and political considerations of this critical meta-lens beg questions about how conclusions are drawn and knowledge might be advanced, and to what degree deliberation should be grounded in democratic ideals (Ravenscroft 2019) or derived from people's lived experience (Brear and Mbonane 2019). However, this raises important questions of procedural and recognition justice, of what, and whose perspectives should be included within consideration of the common good and by what criteria 
this can be validated. Though the emancipatory tradition typically focuses on maximising inclusion (Lo and Spash 2012; Orchard-Webb et al. 2016), this does not mean that all individual values should be included or aggregated, for example where they do not serve society as a whole (Sagoff 1986), or are incompatible with sustainability (Menzel and Green 2013).

Interestingly, a similar tension between descriptive and normative exists with regard to relational values, that can be discussed as a matter for observation (Calcagni et al. 2019; Klain et al. 2017) or an agenda for inclusion and emancipation of non-scientific knowledge (Gould et al. 2019; Stålhammar and Thorén 2019). However, while relational values are not generally put forward as 'better' than instrumental ones, the normative tradition clearly advocates social values as more desirable than individual ones for the purpose of decision-making, as long as the conditions of procedural and recognition justice are reasonably satisfied (Howarth and Wilson 2006; Irvine et al. 2016; Kenter et al. 2016b; Ravenscroft 2019; Zografos and Howarth 2010). This relates also to the dimension of intention on the value lens: when valuation is seen as transformative, it is unlikely that this purpose seeks values to be more self-regarding. Rather, social values are seen as oriented towards more other-regarding perspectives and the consideration of society as a whole (and which may also include non-humans; O'Connor and Kenter 2019; Gould et al. 2019). From this perspective, the individual self-regarding preferences associated with market decisions should not be transferred to the social value domain of the group, or public policy (Mauss 1954; Lo and Spash 2012; Kenter et al. 2014a; Irvine et al. 2016; Ravenscroft 2019). As Sagoff (1986, p303) put it: "Why is it good in itself that a person who wants a Mercedes succeed in getting one? Having a preference is a reason for the person who has it to try to satisfy it. Why should it be a goal of public policy, however to satisfy that preference?".

However, the clear division of self-regarding consumer vs more other-regarding citizen values is seen by some lenses as an abstraction, such as in care ethics and relational axiology, where identities and values are seen as defined by embodied, reciprocal relationships and values, and where self and other are not discretely separated as different objects of regard (Held 2006; Muraca 2016; Gould et al. 2019).

The tension relating to the intention and normativity dimensions of value and epistemic lenses can in part be resolved by recognising that different positions along these dimensions typically correspond to differences at value lens dimensions of scale, provider and concept and the procedural lens dimension of process. Normative meta-lenses are particularly focused on shared and social values in the sense of value to society, formed through a shared social process, and/or expressed by non-individual value-providers. Transcendental values, particularly those relating to environmental sustainability and social justice, are important in the sense that they are seen as ends that steer those processes and that play an important role in contextual value formation, but they are not generally the primary objective of study. There is a goal of providing evidence for interventions, but the social valuation itself can also be seen as an intervention to transform values and/or behaviour or challenge existing institutions. In contrast, descriptive meta-lenses more typically focus on either social values as aggregated individual values, or social values in the sense of transcendental values, mostly by individual providers, and the relations between transcendental and contextual values and behaviour to provide evidence for exogenous interventions. In a small number of studies, the two approaches have been successfully combined where descriptive approaches inform or are integrated with consequent deliberation on the common good (Kenter 2016b; Kenter et al. 2016b; Raymond et al. 2014; Raymond and Kenter 2016; Borsuk et al. 2019). Martino et al. (2019) illustrate that the need for descriptive vs normative valuation also depends on endogenous characteristics of different environmental goods, and how these characteristics interact with social institutions. Further research may consider more deeply when descriptive and normative approaches are most appropriate and when combinations of both add particular value. There is also a need for more explicit evaluations of recognition and procedural justice in critical social valuation, and to what degree, and under which conditions, the transformative objectives of social valuations are met.

\section{Value justifications and frames: shared, social and relational values and our relationship with the natural world}

In recent years, the increasing emphasis on social values within the sustainability field has arisen in parallel with increased attention to relational values, particularly with regard to ecosystem assessment (e.g. Chan et al. 2018, 2016; Muraca 2016; IPBES 2016; Christie et al. 2019b). Several contributions to this feature have considered relational values and their relation with shared, social, instrumental and intrinsic values (Calcagni et al. 2019; Stålhammar and Thorén 2019; Gould et al. 2019; O'Connor and Kenter 2019). Both relational and social strands of thinking evolved, at least in relation to ecosystem assessment and valuation, from increasing recognition of the limitations of mainstream economic valuation and its instrumental value assumptions. This opened up a fuzzy field of nonmonetary, social, cultural or sociocultural values, largely associated with the study of cultural ecosystem services and to some degree indigenous and local knowledge systems, that used a wide array of methods but without much attention to underpinning value, epistemic and procedural 
lenses (Raymond et al. 2014; Scholte et al. 2015). Two interventions signalled different directions: Kenter et al. (2014a, 2015) focused on clarifying the concept, dimensions and types of shared and social values as critiques of the pre-formed, individualist and self-regarding assumptions of mainstream valuation. While shared and social values were considered largely synonymous, social values tended to emphasise social scales whereas shared values tended to refer to social value providers and the outcomes of collective value formation. This discourse (further developed in a special issue of Ecosystem Services, October 2016, mostly by authors associated with the UK National Ecosystem Assessment follow-on; Kenter, 2016a) articulates strongly the social nature of values and the long and short-term processes for socialisation and internalisation of values, with particular regard for integrating deliberative and interpretive approaches as a preferred methodology for assessing shared values (e.g. Orchard-Webb et al. 2016; Edwards et al. 2016; Ranger et al. 2016). Relational values, in the sense of values pertaining to meaningful, non-substitutable relationships between people and their environment, were considered, but primarily from a perspective of their shared-ness within groups, communities, cultures and societies.

In a different intervention, Chan et al. (2016) defined relational values as preferences, principles, and virtues pertaining to relationships. They argue that in practice the instrumental and intrinsic value concepts central to environmental ethics did not capture what matters most to people, and that a distinct bridging concept was needed. This concept has since been elevated to central importance in IPBES (Pascual et al. 2017; Díaz et al. 2018; Christie et al. 2019b). As with social values, the scope of relational values is broad and fuzzy (Stålhammar and Thorén 2019). Relational values can refer to the ethical nature of value as being anthropocentric, yet non-instrumental, in the sense of not open to trade-off (Díaz et al. 2015; Himes and Muraca 2018); or it can relate to the content of transcendental or contextual values as pertaining to relationships (Klain et al. 2017; Gould et al. 2019); or it can refer to a 'relational field' as the source of value, rather than the value object or subject (Muraca 2011, 2016). Importantly, while the dichotomy between intrinsic and instrumental is typically conveyed as a major tension in environmental debates, Stålhammar and Thorén (2019) point out that these value types are somewhat caricatured, and that environmental ethics has long had more nuanced interpretations of instrumental and intrinsic values that are inclusive of relational value justifications (e.g. Naess 1973). As such, the ambition of the relational intervention is perhaps more pragmatic than theoretical, in advancing recognition of the relational nature of how people talk and think about values (Chan et al. 2018).

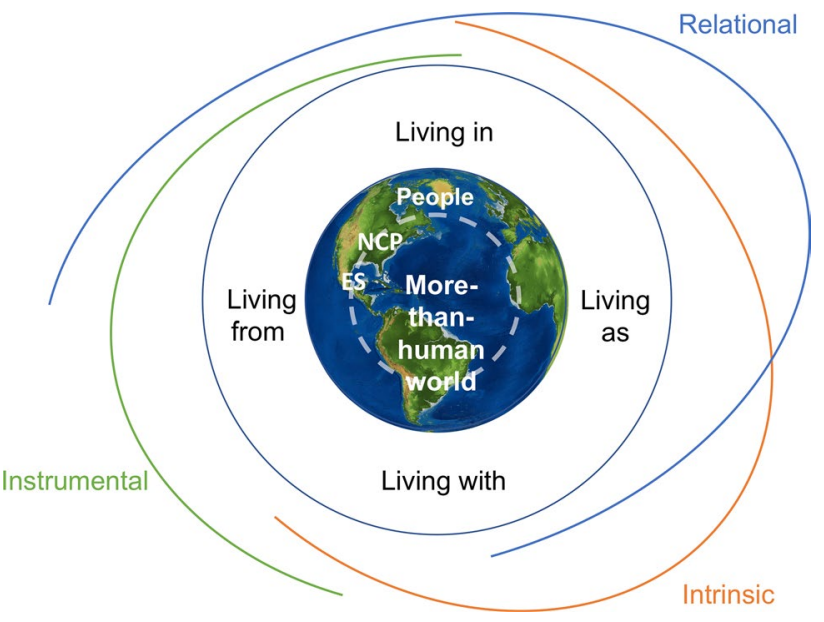

Fig. 4 The Life Value Framework, and the relation between its four frames and instrumental, relational and intrinsic value justifications (adapted from O'Connor and Kenter 2019). ES ecosystem services, NCP nature's contributions to people

Relational values as a boundary concept has thus strategically focused on the dimension of justification. In contrast, the challenges posed by shared and social values to instrumental values are not resolved by developing a noninstrumental concept, but by pointing to the importance of the collective level, understanding the intersubjectivity of values, and development of pluralistic boundary concepts and processes for sharing, aggregating and integrating values that are inclusive of multiple value justifications. As such, shared and social values, and relational values, are complementary constructs both essential for inclusive valuation. Furthermore, the two are closely related; it is hard to imagine any relational values that are not in one dimension or another shared or social (Ishihara 2018), and relationships with nature and place are central in environmental social value formation processes (Kenter 2016a; Ranger et al. 2016; Edwards et al. 2016; Ainsworth et al. 2019; Calcagni et al. 2019; Gould et al. 2019).

An altogether different approach to inclusively communicating values is presented by O'Connor and Kenter (2019), who build on O'Neill et al. (2008) to develop the Life Framework of Value, which moves beyond value justifications to consider valuation in terms of different frames. Here, values are presented simply as what matters, and in relation to the environment this can be framed as living from, with, in and as the world (Fig. 4). Living from reflects the value of the world as a resource, providing for our sustenance and livelihoods. Living in the world points to its role as place, as the stage for our lives. Living with the world points to non-human nature as the other, with whom we co-exist, and which has its own purposes, patterns and cycles. Living as the world points to more-than-human nature as self, with nature and non-humans constitutive of our bodies, psyche 
and spirit individually and collectively, through for example kinship, embodiment, and non-dual spiritual experience (O'Connor and Kenter 2019).

Importantly, while relational values may be particularly associated with living in and as frames, and intrinsic and instrumental values with the with and from frames, the different justifications straddle the frames, pointing to the entwinement of multiple ethical categories in our common experience. For example, a farmer clearing forest for shifting cultivation may be seen through a living from frame, but his livelihood is also likely to be the source of meaningful, non-substitutable relational values, and his clearing activities could support the intrinsic good of biodiversity (e.g. Bayliss-Smith et al. 2003). The authors note that "O'Neill's way of phrasing values in relation to 'living' intuitively imbues a sense of egalitarianism between different values" and "its elegance incites a natural inclination towards including each of the categories [in valuations and decision-making]" (p. $\times 2)$. Differentiating between value frames may be an easier way of communicating nature's values to a broad audience than through more abstract value justifications.

However, further research and debate is needed to better align the need to communicate values effectively in a way that resonates with citizens and policy makers, such as through the Life Framework and relational values, with rigorous explanation of the relationships between different categories. Further, research is needed that builds on discourses and approaches associated with shared and social values to find ways of resolving practical tensions in sustainability practice between different value justifications and frames, enabling more effective value integration.

\section{Value integration and rationalities}

Different forms of value integration were presented in this Special Feature. Papers examined the integration of different types of values, including for example across different scales of values (van Riper et al. 2019) and provider (Kendal and Raymond 2019; Fordham and Robinson 2019) and across different value justifications (Christie et al. 2019b; O'Connor and Kenter 2019; Kronenberg and Andersson 2019). Integration becomes more complex when aligning between epistemic lenses that differ in terms of abstractness and constructedness (Rawluk et al. 2019), for example between values that are lived or embodied, where value is seen as dynamically situated (Raymond et al. 2017) and more objective approaches where values are seen as stable across situations. Such questions point to an urgent need to consider new forms of value integration. Gunton et al. (2017) argued that we need value frameworks that can integrate the place of interest and the scale and subject of interest. They proposed a suite of considerations for valuing ecosystems (e.g. social, economic, aesthetic, jural, sensory, symbolic), to be compared with different stakeholder groups and across different types of places. These frameworks point to the difference between concept and method integration (Kronenberg and Andersson 2019; Guerrero et al. 2018), although arguably method integration needs to be underpinned by conceptual integration, at least if one wishes to avoid unconscious pragmatism where no attention is given to how tensions along different lenses are resolved (Raymond et al. 2014). Most social values for sustainability papers do not discuss the interface between conceptual and methodological integration, and this is an important avenue for future research.

Value integration can achieve different levels or purposes. Kronenberg and Andersson (2019) distinguished full integration through a single measure, comparison of results from selected combinations of methods, and parallel use where there are multiple difficult to compare sets of values. The level of value integration achievable will depend on the degree to which values and value dimensions are deemed logically and axiologically commensurable and value indicators and valuation methods technically compatible.

Different integration levels tend to be informed by different epistemic lens perspectives, including with regard to rationality. Full integration and its demands for commensurability is strongly tied to instrumental rationality (Lockwood 2005). Here the focus is on the choice of suitable indicators where different values are traded-off in the search for an optimal outcome. Values are treated as commensurable by looking to measure them according to a common scale and thus aggregated into a single value indicator, such as through monetisation and many forms of multi-criteria analysis. More limited combination approaches can be linked with bounded rationality, where doing well enough rather than optimising choices is inevitable in many contexts (Simon 1984). Here, incommensurable values may be compared ordinally or nominally (e.g. improvement vs degradation). Values from different methods can also be brought together on the basis of communicative rationality, where values are weighted on the basis of the force of argument rather than analytical criteria, and the realisation of ideals of non-coercion and inclusivity determines to what degree outcomes are rational (Habermas 1984). Here, plural values may be thought of as weakly comparable, which means they should only be compared in terms of practical judgement, rather than on a common scale (Martínez-Alier et al. 1998). For example, O'Connor and Kenter (2019) propose the integration of intrinsic, instrumental and relational values through discussion structured according to the multiple Life Frames, where people are invited to reflect on how different policy scenarios might affect both people and the more-than-human world. Irvine et al. (2016), Kenter (2016a) and Ravenscroft (2019) point out philosophical challenges around deliberative value integration, relating to how much 
different representations and value criteria count, and urging further empirical investigation of how deliberative valuations can act as new democratic spaces for integration based on social learning and communicative rationality.

Given these different value integration rationalities, how can policymakers recognise the diverse values of nature? Here, we need to accept the rationality of 'value pluralism' in that value diversity is an outcome itself. Diverse authors (e.g. Larmore 1987; Kekes 1993) have argued that conflicts between values are not always resolvable. The notion of moral conflict (Stocker 1990) suggests that ethics need not always be action guiding. Instead, respecting plurality involves recognition of diverse pathways of policy formation and implementation. This will require a shift in the culture of policy making and associated capacity building to promote awareness of diverse value traditions and practice in grappling with multiple value lenses and meta-lenses. In terms of deliberation, the principal outcome sought may not be the kind of consensus solutions associated with Habermasian ideals, but providing a forum for plurality, capacity and trust-building. Furthermore, even where values cannot be agreed, it may still be possible to agree on shared meta-values around how to deal with divergent or conflicting values and lenses.

\section{Values, conflict and power}

The consideration of plural values and the challenges of integrating them with each other and into decisions raises key questions of power in navigating such conflicts. Despite real consequences, the interplay between values and power continue to be neglected, especially in empirical valuation studies. This is in part due to the multifaceted nature of both values and power. Power can be both overt and almost imperceptible and exercised through hegemonically privileging certain lenses and meta-lenses (Foucault 1980; Lukes 2005). Power dynamics can influence whose values are expressed or recognised, and which values emerge in contexts, though this is not necessarily transparent. Researchers and practitioners of sustainability science must become attuned to recognising and navigating power as expressed through values and the lenses by which we examine them.

The interplay between social values and power can occur in many ways. A dominant scientific framing of sustainability privileges one way of knowing, which can depoliticise inherently political challenges (Sletto 2008). Examples include the concepts of the Anthropocene (Haraway et al. 2015) and sustainability itself (Ferreira 2017), which homogenise social drivers apolitically. Consciously or unconsciously privileging one set of social value lenses over others can manifest in social-ecological injustices (Collard et al. 2018). Certain values (e.g. economic, moral, religious, scientific, etc.) of particular groups (e.g. different social classes) will be favoured in policy and decision-making through exercise of power, for example through privileging of economic value above all else (Demaria 2010). In contrast, lenses and languages of valuation, and consequently values, associated with indigenous and local knowledge systems are often ignored in decision-making (Martinez-Alier 2009; Christie et al. 2019b). Further, meta-values encapsulated in dominant lenses, including ideas of social memory and how the future should be (Rawluk and Curtis 2016), can cause people to silence values that don't match expectations, including in deliberative processes (Orchard-Webb et al. 2016; Lo and Spash 2012).

There are many ways in which power can be exercised in order to direct, control or regulate the conduct of people, in overt and subtle ways (Foucault and Rabinow 1997), for example, through discursive strategies of power-knowledge embedded in different 'governmentalities', such as Sovereignty, Discipline, Neoliberalism and Truth, as an art of government (Foucault et al. 2008). According to different technologies of power exerted in a historical context, these governmentalities affect the values that people are able to adopt in their lives. Given that values are crucial aspects of the choices, decisions, and behaviours of people related to sustainability, the interplay between how power is exercised, the values that people adopt, and the construction of individuals' identities is key to understand environmental governance and its outcomes (Agrawal et al. 2005; D'Alisa and Kallis 2016).

While ontological and epistemological differences can be a source of contestation (Rawluk et al. 2019), tensions around power inevitably arise in relation to any form of social values assessment in practice, though are often not acknowledged. In particular, there is a need for more attention to power relations in diverse processes of value formation, socialisation and internalisation, such as by Calcagni et al. (2019) who consider the impact of communication and market strategies influencing value creation on social media. Even in deliberative value formation characterised by ideals of non-coercive communicative rationality, such ideals can only be approximated, as in the real-world, unconscious power relations cannot be fully ironed out (Orchard-Webb et al. 2016; Kadlec and Friedman 2007). Intractable controversies inevitably remain, demanding specific, contextual answers at the level of practice (Pellizzoni 2001). Further, in sustainability practice, an important barrier for realising pro-sustainability social values are people's limited power and control to change their unsustainable practices resulting from unmet wellbeing-related needs (Brear and Mbonane 2019; Huxley and Yiftachel 2000).

Thus, sustainability that manifests social-ecological justice requires centring on both social values and power. 
If other-regarding transcendental values that underpin the ethos of sustainability, such as equity, generosity and care, are to be promoted, there is a precursory requirement to transparently observe diversities of values and needs alongside privileging mechanisms of power. In the field of valuation, scholars may need to become more comfortable with relational and post-structuralist meta-lenses, since power is observed more easily through these (Foucault 1980). In line with Geels et al. (2017), Smith et al. (2005) and Everard et al. (2016), considering values through multiple value, epistemic and procedural lenses is critical because socio-technical transition pathways towards sustainable systems imply necessarily value-oriented governance systems, which are affected by the interplays between technologies of power, the institutional system, and the processes of pro-sustainability value socialisation.

\section{Conclusions}

In this paper, we have considered key theoretical and practical tensions in the burgeoning field of social values of sustainability. These tensions relate to important dimensions of values that characterise the lenses and epistemic and procedural meta-lenses through which different traditions conceive and perceive these values. Key avenues for future research relating to these tensions include:

1. Exploration of relations between collective and individual values, and the dynamic internalisation and socialisation processes by which values transfer up and down between individuals and multiple social scales of value provider;

2. Investigation of crisis-triggers for pro-sustainability value-change and levers for 'rippling out' changes;

3. Conceptual development and empirical exploration of proto-values;

4. Application of interventions based on value awareness, activation and congruence within sustainability contexts and their upscaling from individualistic to social;

5. Evaluation of values-based interventions that take a generalised vs place-based perspective;

6. Further development of the Life Framework as a novel way of organising and communicating why the natural world matters;

7. The interface between value, conceptual and methodological pluralism, value integration and comparative and combined use of multiple rationalities for valuation;

8. Deliberative mechanisms to address conflicts between values at different spatiotemporal and social scales, between different value justifications and Life Frames and between different value and epistemic lenses;
9. More explicit evaluations of recognition and procedural justice in critical social valuation, and under which conditions transformative objectives of social valuations are met;

10. The interplay between how power is exercised and the values that people adopt across different institutions and contexts;

11. The development of new languages of valuation that are better reflective of relational, constructivist and poststructuralist perspectives;

12. Understanding mechanisms whereby certain lenses are privileged over others in different decision-contexts, and capacity building for understanding and drawing on multiple value, epistemic and procedural lenses in decision-making.

The large number of dimensions of values to which these questions point reflect that sustainability issues are by and large complex and wicked problems. Addressing such issues requires us to navigate transcendental and contextual values at multiple spatiotemporal scales, between individuals and collectives, across different potentially conflicting value justifications, frames and rationalities, and with close attention to power relations in such conflicts, both within and between different value articulating institutions. Effective navigation requires charts, beacons and experience. This paper has sought to scout the terrain providing a multidimensional interpretation of the messy social values landscape. Such a map is crucial in communicating with fellow travellers where one is, in the sense of what values one is articulating and from which vantage point. Understanding of tensions provides beacons to shed light on crucial areas of conflict, where we need to pay particular attention in our journeys of sustainability science and practice. At these points, experience of engaging not just with the landscape and its map but with fellow travellers becomes vital, as the terrain is too challenging for any tradition to tackle on its own. Crucially, all values around sustainability have a social dimension. A juxtaposition between individual instrumental values and social, shared, cultural, non-instrumental or relational values is thus not helpful-rather we must help each other understand what dimensions of the value landscape we are viewing and through what lens. At these junctions, by loving the mess and enjoying the thrill of exploration, conflict can become a space of creative dynamism where new concepts, methods and approaches can be born. The mess does not need resolving but engaging with. This requires building capacity with researchers and practitioners: learning to navigate and learning to love, by embracing the plurality of how we conceive and articulate values in research, decision mechanisms and boundary spaces-all are ultimately social processes of valuation. 
Acknowledgements This research was supported by the Valuing Nature Programme funded by the UK Natural Environment Research Council (NERC) under grant reference NE/M005410/1.

Open Access This article is distributed under the terms of the Creative Commons Attribution 4.0 International License (http://creativeco mmons.org/licenses/by/4.0/), which permits unrestricted use, distribution, and reproduction in any medium, provided you give appropriate credit to the original author(s) and the source, provide a link to the Creative Commons license, and indicate if changes were made.

\section{References}

Agrawal A, Gupta A, Hathaway M, Narotzky S, Raffles H, Skaria A et al (2005) Environmentality: community, intimate government, and the making of environmental subjects in Kumaon, India. Curr Anthropol 46(2):161-190

Ainscough J, Wilson M, Kenter JO (2018) Ecosystem services as a post-normal field of science. Ecosyst Serv 31:93-101. https:// doi.org/10.1016/j.ecoser.2018.03.021

Ainsworth GB, Kenter JO, O'Connor S, Daunt FJH, Young JC (2019) A fulfilled human life: sense of place and cultural identity in the marine environment. Ecosyst Serv (In press)

Bardi A, Goodwin R (2011) The dual route to value change: individual processes and cultural moderators. J Cross Cult Psychol 42:271287. https://doi.org/10.1177/0022022110396916

Bayliss-Smith T, Hviding E, Whitmore T (2003) Rainforest composition and histories of human disturbance in Solomon Islands. J Hum Environ 32:346-352

Borsuk M, Mavrommati G, Samal N, Zuidema S, Wollheim W, Rogers S, Thorn A, Lutz D, Mineau M, Grimm C, Wake C, Howarth R, Gardner K (2019) Deliberative multiattribute valuation of ecosystem services across a range of regional land-use, socioeconomic, and climate scenarios for the upper Merrimack River watershed, New Hampshire. USA. Ecol Soc 24:11. https://doi. org/10.5751/ES-10806-240211

Brear MR, Mbonane BM (2019) Social values, needs, needs-fulfilment practices and sustainable water-energy-food resource use: a rural Swazi case study. Sustain Sci. https://doi.org/10.1007/ s11625-019-00717-5

Calcagni F, Amorim Maia AT, Connolly JJT, Langemeyer J (2019) Digital co-construction of relational values: understanding the role of social media for sustainability. Sustain Sci. https://doi. org/10.1007/s11625-019-00672-1

Chan KMA, Balvanera P, Benessaiah K et al (2016) Opinion: why protect nature? Rethinking values and the environment. Proc Natl Acad Sci USA 113:1462-1465. https://doi.org/10.1073/ pnas. 1525002113

Chan KMA, Gould RK, Pascual U (2018) Editorial overview: relational values: what are they, and what's the fuss about?". Curr Opin Environ Sustain 35:A1-A7

Christie I, Gunton RM, Hejnowicz AP (2019a) Sustainability and the common good: catholic social teaching and "integral ecology" as contributions to a framework of social values for sustainability transitions. Sustain Sci. https://doi.org/10.1007/s11625-01900691-y

Christie M, Martin-Lopez B, Church A et al (2019b) Understanding the diversity of values of "Nature's contributions to people": insights from the IPBES assessment of Europe and Central Asia. Sustain Sci. https://doi.org/10.1007/s11625-019-00716-6
Collard R-C, Harris LM, Heynen N, Mehta L (2018) The antinomies of nature and space. Environ Plann E Nat Space 1(1-2):3-24

D'Alisa G, Kallis G (2016) A political ecology of maladaptation: insights from a Gramscian theory of the State. Global Environ Change 38:230-242

Demaria F (2010) Shipbreaking at Alang-Sosiya (India): an ecological distribution conflict. Ecol Econ 70:250-260. https://doi. org/10.1016/j.ecolecon.2010.09.006

Díaz S, Demissew S, Carabias J et al (2015) The IPBES conceptual framework-connecting nature and people. Curr Opin Environ Sustain 14:1-16. https://doi.org/10.1016/j.cosust.2014.11.002

Díaz S, Pascual U, Stenseke M et al (2018) Assessing nature's contributions to people. Science 359:270-272. https://doi.org/10.1126/ science.aap8826

Edwards DM, Collins TM, Goto R (2016) An arts-led dialogue to elicit shared, plural and cultural values of ecosystems. Ecosyst Serv 21:319-328. https://doi.org/10.1016/j.ecoser.2016.09.018

Eriksson ME, van Riper CJ, Leitschuh B, Bentley-Brimer A, Rawluk A, Raymond CC, Kenter JO (2019) Social learning as a link between the individual and the collective: evaluating a deliberation of social values. Sustain Sci. https://doi.org/10.1007/s1162 5-019-00725-5

Ernstson H (2013) The social production of ecosystem services: a framework for studying environmental justice and ecological complexity in urbanized landscapes. Landscape Urban Plann 109(1):7-17

Everard M, Reed MS, Kenter JO (2016) The ripple effect: institutionalising pro-environmental values to shift societal norms and behaviours. Ecosyst Serv 21:230-240. https://doi.org/10.1016/j.ecose r.2016.08.001

Ferreira F (2017) Critical sustainability studies: a holistic and visionary conception of socio-ecological conscientization. Journal of Sustainability Education 13 (online)

Ford JD, Cameron L, Rubis J et al (2016) Including indigenous knowledge and experience in IPCC assessment reports. Nat Clim Chang 6:349-353. https://doi.org/10.1038/nclimate2954

Fordham A, Robinson G (2019) Identifying the social values driving corporate social responsibility. Sustain Sci. https://doi. org/10.1007/s11625-019-00720-w

Foucault M (1980) Power/knowledge: selected interviews and other writings, 1972-1977. Pantheon Books, New York

Foucault M, Rabinow P (1997) Essential works of Foucault, 19541988. Ethics 742 subjectivity and truth. Gallimard

Foucault M, Davidson A, Burchell G (2008) The birth of biopolitics: lectures at the Collège de France, 1978-1979. Springer, New York

Funtowicz SO, Ravetz JR (1993) Science for the post-normal age. Futures 25:739-755

Gavin MC, McCarter J, Berkes F et al (2018) Effective biodiversity conservation requires dynamic, pluralistic, partnership-based approaches. Sustainability 10:1846. https://doi.org/10.3390/ su10061846

Geels FW, Sovacool BK, Schwanen T, Sorrell S (2017) Sociotechnical transitions for deep decarbonization. Science 357(6357):1242-1244

Goldstein LJ (2015) Conceptual tension: essays on kinship, politics and individualism. Lexington Books, London

Gould R, Pai M, Muraca B, Chan KMA (2019) He 'ike 'ana ia i ka pono (It is a recognizing of the right thing): how one indigenous worldview informs relational values and social values. Sustain Sci. https://doi.org/10.1007/s11625-019-00721-9

Guerrero AM, Bennett NJ, Wilson KA, Carter N, Gill D, Mills M, Ives CD, Selinske MJ, Larrosa C, Bekessy S, Januchowski-Hartley FA, Travers H, Wyborn CA, Nuno A (2018) Achieving the promise of integration in social-ecological research: a review 
and prospectus. Ecol Soc 23(3):38. https://doi.org/10.5751/ ES-10232-230338

Gunton R, Klenke R, Paloniemi R, Gavish Y, Marsh C, Kunin W, Henle K (2014) The meaning of "scale". Scaling in ecology and biodiversity conservation. Pensoft Publishers, Sofia, pp 19-22

Gunton RM, van Asperen EN, Basden A et al (2017) Beyond ecosystem services: valuing the invaluable. Trends Ecol Evol 32:249257. https://doi.org/10.1016/j.tree.2017.01.002

Habermas J (1984) The theory of communicative action, volume I. Beacon, Boston, MA

Haraway D, Ishikawa N, Gilbert SF et al (2015) Anthropologists are talking-about the anthropocene. Ethnos 81:535-564. https:// doi.org/10.1080/00141844.2015.1105838

Held V (2006) The ethics of care: personal, political, and global. In: Copp D (ed) The Oxford handbook of 937 ethical theory. Oxford University Press, Oxford

Himes A, Muraca B (2018) Relational values: the key to pluralistic valuation of ecosystem services. Curr Opin Environ Sustain 35:1-7. https://doi.org/10.1016/j.cosust.2018.09.005

Hockley N (2014) Cost-benefit analysis: a decision-support tool or a venue for contesting ecosystem knowledge? Environ Plann C 32:283-300. https://doi.org/10.1068/c1384j

Horcea-Milcu A, Abson D, Apetrei C et al (2019) Values in transformational sustainability science: four perspectives for change. Sustain Sci. https://doi.org/10.1007/s11625-019-00656-1

Howarth RB, Wilson MA (2006) A theoretical approach to deliberative valuation: aggregation by mutual consent. Land Econ 82:1-16. https://doi.org/10.3368/le.82.1.1

Hulme M (2011) Meet the humanities. Nat Clim Change 1:177-179. https://doi.org/10.1038/nclimate1150

Huxley M, Yiftachel O (2000) New paradigm or old Myopia? Unsettling the communicative turn in planning theory. J Plann Educ Res 19:333-342. https://doi.org/10.1177/0739456X0001900402

IPBES (2016) Preliminary guide regarding diverse conceptualisation of multiple values of nature and its benefits, including biodiversity and ecosystem functions and services. IPBES-4-INF-13-EN-1. IPBES Secretariat, Bonn

IPBES (2019) Summary for policymakers of the global assessment report on biodiversity and ecosystem services of the intergovernmental science-policy platform on biodiversity and ecosystem services. IPBES Secretariat, Bonn. https://www.ipbes.net/sites/ default/files/downloads/spm_unedited_advance_for_posting_htn. pdf. Accessed 1 June 2019

Irvine KN, O’Brien L, Ravenscroft N, Cooper N, Everard M, Fazey I, Reed MS, Kenter JO (2016) Ecosystem services and the idea of shared values. Ecosyst Serv 21:184-193. https://doi. org/10.1016/j.ecoser.2016.07.001

Ishihara H (2018) Relational values from a cultural valuation perspective: how can sociology contribute to the evaluation of ecosystem services? Curr Opin Environ Sustain. https://doi.org/10.1016/j. cosust.2018.10.016

Ives CD, Fischer J (2017) The self-sabotage of conservation: reply to Manfredo et al. Conserv Biol 31:1483-1485. https://doi. org/10.1111/cobi.13025

Ives CD, Kendal D (2014) The role of social values in the management of ecological systems. J Environ Manage 144:67-72. https://doi. org/10.1016/j.jenvman.2014.05.013

Ives CD, Kidwell J (2019) Religion and social values for sustainability. Sustain Sci. https://doi.org/10.1007/s11625-019-00657-0

Jobstvogt N, Hanley N, Hynes S et al (2014a) Twenty thousand sterling under the sea: estimating the value of protecting deep-sea biodiversity. Ecol Econ 97:10-19. https://doi.org/10.1016/j.ecole con.2013.10.019

Jobstvogt N, Watson V, Kenter JO (2014b) Looking below the surface: the cultural ecosystem service values of UK marine protected areas (MPAs). Ecosyst Serv 10:97-110. https://doi.org/10.1016/j. ecoser.2014.09.006

Kadlec A, Friedman W (2007) Deliberative democracy and the problem of power. J Public Deliberat 3(1), Article 8

Kekes J (1993) The morality of pluralism. Princeton University Press, Princeton

Kendal D, Raymond C (2019) Understanding pathways to shifting values over time in the context of social-ecological systems. Sustain Sci. https://doi.org/10.1007/s11625-018-0648-0

Kenter JO (2016a) Editorial: shared, plural and cultural values. Ecosyst Serv 21:175-183. https://doi.org/10.1016/j.ecoser.2016.10.010

Kenter JO (2016b) Integrating deliberative monetary valuation, systems modelling and participatory mapping to assess shared values of ecosystem services. Ecosyst Serv 21:291-307. https://doi. org/10.1016/j.ecoser.2016.06.010

Kenter JO, Reed MS, Irvine KN, O’Brien L, Brady E, Bryce R, Christie M, Church A, Cooper N, Davies A, Hockley N, Fazey I, Jobstvogt N, Molloy C, Orchard-Webb J, Ravenscroft N, Ryan M, Watson V (2014a) UK national ecosystem assessment followon phase. Work Package Report 6: shared, plural and cultural values of ecosystems. UNEP-WCMC, Cambridge. https://doi. org/10.13140/rg.2.1.1275.6565

Kenter JO, Reed MS, Everard M, Irvine KN, O'brien EA, Molloy C, Bryce R, Brady E, Christie M, Church A, Collins T, Cooper N, Davies A, Edwards D, Evely A, Fazey I, Goto R, Hockley N, Jobstvogt N, Orchard-Webb J, Ravenscroft N, Ryan M, Watson V (2014b) UK national ecosystem assessment follow-on shared, plural and cultural values: a handbook for decisionmakers. UNEP-WCMC, Cambridge. http://doi.org/10.13140/ RG.2.1.4683.5281

Kenter JO, O'Brien L, Hockley N, Ravenscroft N, Fazey I, Irvine KN, Reed MS, Christie M, Brady E, Bryce R, Church A, Cooper N, Davies A, Evely A, Everard M, Fish R, Fisher JA, Jobstvogt N, Molloy C, Orchard-Webb J, Ranger S, Ryan M, Watson V, Williams S (2015) What are shared and social values of ecosystems? Ecol Econ 111:86-99

Kenter JO, Bryce R, Christie M, Cooper N, Hockley N, Irvine KN, Fazey I, O'Brien L, Orchard-Webb J, Ravenscroft N, Raymond CM, Reed MS, Tett P, Watson V (2016a) Shared values and deliberative valuation: future directions. Ecosyst Serv 21:358371. https://doi.org/10.1016/j.ecoser.2016.10.006

Kenter JO, Jobstvogt N, Watson V, Irvine K, Christie M, Bryce R (2016b) The impact of information, value-deliberation and group-based decision-making on values for ecosystem services: integrating deliberative monetary valuation and storytelling. Ecosyst Serv 21:270-290. https://doi.org/10.1016/j.ecose r.2016.06.006

Kenter JO, Reed MS, Fazey I (2016c) The deliberative value formation model. Ecosyst Serv 21:194-207. https://doi.org/10.1016/j. ecoser.2016.09.015

Kenyon W, Hanley N, Nevin C (2001) Citizens' juries: an aid to environmental valuation? Environ Plann C 19:557-566. https://doi. org $/ 10.1068 / \mathrm{c} 4 \mathrm{~s}$

Klain SC, Olmsted P, Chan KMA, Satterfield T (2017) Relational values resonate broadly and differently than intrinsic or instrumental values, or the New Ecological Paradigm. PLoS One 12:e0183962. https://doi.org/10.1371/journal.pone.0183962

Kollmuss A, Agyeman J (2002) Mind the gap: why do people act environmentally and what are the barriers to pro-environmental behavior? Environ Educ Res 8(3):239-260

Kronenberg J (2014) What can the current debate on ecosystem services learn from the past? Lessons from economic ornithology. Geoforum 55:164-177. https://doi.org/10.1016/j.geofo rum.2014.06.011

Kronenberg J, Andersson E (2019) Integrating social values with other value dimensions: parallel use vs. combination vs. full 
integration. Sustain Sci. https://doi.org/10.1007/s11625-01900688-7

Larmore C (1987) Patterns of moral complexity. Cambridge University Press, Cambridge

Lo AY, Spash CL (2012) Deliberative monetary valuation: in search of a democratic and value plural approach to environmental policy. J Econ Surv 27:768-789. https://doi.org/10.111 1/j.1467-6419.2011.00718.x

Lockwood M (2005) Integration of natural area values: conceptual foundations and methodological approaches. Australas J Environ Manag 12:8-19. https://doi.org/10.1080/14486563.2005.97251 00

Lukes S (2005) Power: a radical view, 2nd edn. Palgrave Macmillan, Basingstoke

Manfredo MJ, Teel TL, Gavin MC, Fulton D (2014) Considerations in representing human individuals in social-ecological models. In: Manfredo M, Vaske J, Rechkemmer A, Duke EA (eds) Understanding society and natural resources: forging new strands of integration across the social sciences. Springer, New York, pp $137-158$

Manfredo MJ, Bruskotter JT, Teel TL et al (2017) Why social values cannot be changed for the sake of conservation. Conserv Biol 31:772-780. https://doi.org/10.1111/cobi.12855

Martinez-Alier J (2009) Social metabolism, ecological distribution conflicts, and languages of valuation. Capital Nat Soc 20(1):5887. https://doi.org/10.1080/10455750902727378

Martínez-Alier J, Munda G, O’Neill J (1998) Weak comparability of values as a foundation for ecological economics. Ecol Econ 26:277-286. https://doi.org/10.1016/S0921-8009(97)00120-1

Martino S, Tett P, Kenter JO (2019) The interplay between economics, legislative power and social influence examined through a social-ecological framework for marine ecosystems services. Sci Total Environ 651:1388-1404. https://doi.org/10.1016/j.scito tenv.2018.09.181

Massenberg JR (2019) Social values and sustainability: a retrospective view on the contribution of economics. Sustain Sci. https://doi. org/10.1007/s11625-019-00693-w

Mauss M (1954) The gift: forms and functions of exchange in archaic societies, 2000 edn. W. W. Norton \& Company, New York

Menzel S, Green TL (2013) Sovereign citizens and constrained consumers: why sustainability requires limits on choice. Environ Values 22(1):59-79. https://doi.org/10.3197/096327113X13528 328798273

Muraca B (2011) The map of moral significance: a new axiological matrix for environmental ethics. Environ Value 20:375-396. https://doi.org/10.3197/096327111X13077055166063

Muraca B (2016) relational values: a whiteheadian alternative for environmental philosophy and global environmental justice. Balkan J Philos 8:19-38. https://doi.org/10.5840/bjp2016813

Naess A (1973) The shallow and the deep, long-range ecology movement. Inquiry Interdiscip J Philos 16:95-100

O'Brien K, Wolf J (2010) A values-based approach to vulnerability and adaptation to climate change. Wiley Interdiscip Rev Clim Change 1:232-242

O'Connor S, Kenter J (2019) Making intrinsic values work: integrating intrinsic values of more-than human nature through the Life Framework of Values. Sustain Sci. https://doi.org/10.1007/s1162 5-019-00715-7

O’Neill J, Holland A, Light A (2008) Environmental values. Routledge, Abingdon

Orchard-Webb J, Kenter JO, Bryce R, Church A (2016) Deliberative democratic monetary valuation to implement the ecosystem approach. Ecosyst Serv 21:308-318. https://doi.org/10.1016/j. ecoser.2016.09.005
Parks S, Gowdy J (2013) What have economists learned about valuing nature? A review essay. Ecosyst Serv 3:e1-e10. https://doi. org/10.1016/j.ecoser.2012.12.002

Pascual U, Balvanera P, Díaz S et al (2017) Valuing nature's contributions to people: the IPBES approach. Curr Opin Environ Sustain. https://doi.org/10.1016/j.cosust.2016.12.006

Pellizzoni L (2001) The myth of the best argument: power, deliberation and reason. Br J Sociol 52:59-86. https://doi.org/10.1080/00071 310020023037

Ranger S, Kenter JO, Bryce R et al (2016) Forming shared values in conservation management: an interpretive-deliberative-democratic approach to including community voices. Ecosyst Serv 21:344-357. https://doi.org/10.1016/j.ecoser.2016.09.016

Ravenscroft N (2019) A new normative economics for the formation of shared social values. Sustain Sci. https://doi.org/10.1007/s1162 5-018-0652-4

Rawluk A, Curtis A (2016) Reconciling contradictory narratives of landscape change using the adaptive cycle: a case study from southeastern Australia. Ecol Soc 21(1):17. https://doi. org/10.5751/ES-08245-210117

Rawluk A, Ford RM, Neolaka FL, Williams KJ (2017) Public values for integration in natural disaster management and planning: a case study from Victoria, Australia. J Environ Manage 185:11-20

Rawluk A, Ford R, Anderson N, Williams K (2019) Exploring multiple dimensions of values and valuing: a conceptual framework for mapping and translating values for social-ecological research and practice. Sustain Sci. https://doi.org/10.1007/s11625-018-0639-1

Raymond CM, Kenter JO (2016) Transcendental values and the valuation and management of ecosystem services. Ecosyst Serv 21:241-257. https://doi.org/10.1016/j.ecoser.2016.07.018

Raymond I, Raymond CM (2019) Positive psychology perspectives on social values and their application to intentionally delivered sustainability interventions. Sustain Sci. https://doi.org/10.1007/ s11625-019-00705-9

Raymond CM, Kenter JO, Plieninger T, Turner NJ, Alexander KA (2014) Comparing instrumental and deliberative paradigms underpinning the assessment of social values for cultural ecosystem services. Ecol Econ 107:145-156. https://doi.org/10.1016/j. ecolecon.2014.07.033

Raymond CM, Giusti M, Barthel S (2017) An embodied perspective on the co-production of cultural ecosystem services: toward embodied ecosystems. J Environ Plann Manage 1:1-22. https:// doi.org/10.1080/09640568.2017.1312300

Raymond CM, Kenter JO, Kendal D, van Riper C, Rawluk A (2018) Call for papers for "Theoretical traditions in social values for sustainability". Sustain Sci 13:269-271. https://doi.org/10.1007/ s11625-018-0537-6

Raymond CM, Kenter JO, van Riper C, Rawluk A, Kendal D (2019) Editorial overview: theoretical traditions in social values for sustainability. Sustain Sci. https://doi.org/10.1007/s11625-01900723-7

Rokeach M (1973) The nature of human values. Free Press, New York Sagoff M (1986) Values and preferences. Ethics 96:301-316

Scholte SSK, van Teeffelen AJA, Verburg PH (2015) Integrating sociocultural perspectives into ecosystem service valuation: a review of concepts and methods. Ecol Econ 114:67-78. https://doi. org/10.1016/j.ecolecon.2015.03.007

Schroeder H (2013) Sensing value in place. In: Stewart W, Williams D, Kruger L (eds) Place-based conservation: perspectives from the social sciences. Springer, Dordrecht, pp 131-155

Schwartz SH, Cieciuch J, Vecchione M, Davidov E, Fischer R, Beierlein C, Ramos A, Verkasalo M, Lönnqvist J-E, Demirutku K (2012) Refining the theory of basic individual values. J Pers Soc Psychol 103:663

Simon HA (1984) Models of bounded rationality, volume 1: economic analysis and public policy. MIT Press Books, Cambridge 
Sletto B (2008) The knowledge that counts: institutional identities, policy science, and the conflict over fire management in the Gran Sabana, Venezuela. World Dev 36(10):1938-1955

Smith A, Stirling A, Berkhout F (2005) The governance of sustainable socio-technical transitions. Res Policy 34(10):1491-1510

Stålhammar S, Thorén H (2019) Three perspectives on relational values of nature. Sustain Sci. https://doi.org/10.1007/s11625-019-00718 $-4$

Steger C, Hirsch S, Evers C, Branoff B, Petrova M, Nielsen-Pincus M, Wardropper C, van Riper CJ (2018) Ecosystem services as boundary objects for transdisciplinary collaboration. Ecol Econ $143: 153-160$

Stets JE, Burke PJ (2000) Identity theory and social identity theory. Soc Psychol 63:224-237. https://doi.org/10.2307/2695870

Stocker M (1990) Plural and conflicting values. Clarendon Press, Oxford

Strand R (2017) Post-normal science. In: Spash CL (ed) Routledge handbook of ecological economics: nature and society. Routledge, Abington

Trope Y, Liberman N (2010) Construal-level theory of psychological distance. Psychol Rev 117:440

Urama KC, Hodge I (2006) Participatory environmental education and willingness to pay for river basin management: empirical evidence from Nigeria. Land Econ 82:542-561

van Riper CJ, Landon A, Kidd S, Bitterman P, Fitzgerald LA, Granek EF, Ibarra S, Iwaniec D, Raymond CM, Toledo D (2017)
Incorporating socio-cultural phenomena into ecosystem service valuation: the importance of critical pluralism. Bioscience 67(3):233-244

van Riper C, Thiel A, Penker M, Braito M, Landon A, Thomsen J, Tucker C (2018) Incorporating multilevel values into the socialecological systems framework. Ecol Soc 23:art25. https://doi. org/10.5751/es-10047-230325

van Riper CJ, Winkler-Schor S, Stamberger L et al (2019) Integrating multi-scale values and pro-environmental behavior in a protected area. Sustain Sci. https://doi.org/10.1007/s11625-019-00677-w

Wamsler C, Brossmann J, Hendersson H, Kristjansdottir R, McDonald C, Scarampi P (2018) Mindfulness in sustainability science, practice, and teaching. Sustain Sci 13(1):143-162. https://doi. org/10.1007/s11625-017-0428-2

Williams DR (2014) Making sense of "place": reflections on pluralism and positionality in place research. Landscape Urban Plann 131:74-82. https://doi.org/10.1016/j.landurbplan.2014.08.002

Zografos C, Howarth RB (2010) Deliberative ecological economics for sustainability governance. Sustainability 2010:3399-3417

Publisher's Note Springer Nature remains neutral with regard to jurisdictional claims in published maps and institutional affiliations.

\section{Affiliations}

Jasper O. Kenter ${ }^{1} \mathbb{D}$. Christopher M. Raymond ${ }^{2,3,4} \cdot$ Carena J. van Riper $^{5}$. Elaine Azzopardi ${ }^{1}$ Michelle R. Brear ${ }^{6,7}$. Fulvia Calcagni $^{8} \cdot$ Ian Christie ${ }^{9}$ Michael Christie ${ }^{10}$ - Anne Fordham ${ }^{11} \cdot$ Rachelle K. Gould $^{12}$. Christopher D. Ives ${ }^{13}$. Adam P. Hejnowicz ${ }^{14}$. Richard Gunton ${ }^{15}$. Andra-loana Horcea-Milcu ${ }^{16}$. Dave Kendal ${ }^{17}$. Jakub Kronenberg ${ }^{18}$. Julian R. Massenberg ${ }^{19}$. Seb O'Connor ${ }^{20}$. Neil Ravenscroft ${ }^{21}$. Andrea Rawluk ${ }^{22}$. Ivan J. Raymond ${ }^{23}$. Jorge Rodríguez-Morales ${ }^{24}$. Samarthia Thankappan ${ }^{1}$

1 Department of Environment and Geography, University of York, York, UK

2 Helsinki Institute of Sustainability Science, University of Helsinki, Helsinki, Finland

3 Ecosystems and Environment Research Program, Faculty of Biological and Environmental Sciences, University of Helsinki, Helsinki, Finland

4 Department of Environmental and Resource Economics, Faculty of Agriculture and Forestry, University of Helsinki, Helsinki, Finland

5 Department of Natural Resources and Environmental Sciences, University of Illinois at Urbana-Champaign, Urbana-Champaign, USA

6 Faculty of Education and Afromontane Research Unit, University of the Free State-Qwaqwa Campus, Phuthaditjhaba, South Africa

7 Global Public Health Unit, Monash University, Melbourne, Australia

8 Institute of Environmental Science and Technology (ICTA), Universitat Autònoma de Barcelona, Bellaterra, Spain

9 Centre for Environment and Sustainability, University of Surrey, Guildford, UK
10 Aberystwyth Business School, Aberystwyth University, Aberystwyth, UK

11 University of South Australia, Adelaide, Australia

12 Environmental Program and Rubenstein School of Environment and Natural Resources, University of Vermont, Burlington, USA

13 School of Geography, University of Nottingham, Nottingham, UK

14 Department of Biology, University of York, York, UK

15 Department of Biological Sciences, University of Leeds, Leeds, UK

16 Faculty of Sustainability, Leuphana University of Lüneburg, Lüneburg, Germany

17 School of Technology, Environments and Design, University of Tasmania, Hobart, Australia

18 Department of Regional Economics and the Environment, University of Łódź, Łódź, Poland

19 Department of Economics, Helmholtz Centre for Environmental Research, UFZ, Leipzig, Germany

20 School of Fine Art, History of Art and Cultural Studies, University of Leeds, Leeds, UK 
21 School of Real Estate and Land Management, Royal Agricultural University, Cirencester, UK

22 School of Ecosystem and Forest Sciences, University of Melbourne, Melbourne, Australia
23 Life Buoyancy Institute, Adelaide, Australia

24 Stockholm Environment Institute, Stockholm, Sweden 